Nova Southeastern University

2016

\title{
Assistive Technology Instruction in Teacher Professional Development
}

David N. Schaaf

Nova Southeastern University, ds1954@nova.edu

This document is a product of extensive research conducted at the Nova Southeastern University College of Engineering and Computing. For more information on research and degree programs at the NSU College of Engineering and Computing, please click here.

Follow this and additional works at: https://nsuworks.nova.edu/gscis_etd

Part of the Computer Sciences Commons

\section{Share Feedback About This Item}

\section{NSUWorks Citation}

David N. Schaaf. 2016. Assistive Technology Instruction in Teacher Professional Development. Doctoral dissertation. Nova Southeastern University. Retrieved from NSUWorks, College of Engineering and Computing. (985)

https://nsuworks.nova.edu/gscis_etd/985.

This Dissertation is brought to you by the College of Engineering and Computing at NSUWorks. It has been accepted for inclusion in CEC Theses and Dissertations by an authorized administrator of NSUWorks. For more information, please contact nsuworks@nova.edu. 


\section{Assistive Technology Instruction in Teacher Professional Development}

by

David N. Schaaf

A dissertation submitted in partial fulfillment of the requirements for the degree of Doctor of Philosophy

in

Computing Technology in Education

College of Engineering and Computing

Nova Southeastern University 
We hereby certify that this dissertation, submitted by David Schaaf, conforms to acceptable standards and is fully adequate in scope and quality to fulfill the dissertation requirements for the degree of Doctor of Philosophy.

Gertrude W. Abramson, Ed.D

Date

Chairperson of Dissertation Committee

Martha M. Snyder, Ph.D.

Date

Dissertation Committee Member

Cordelia R. Twomey, Ph.D.

Date

Dissertation Committee Member

Approved:

Yong X. Tao, Ph.D., P.E., FASME

Date

Dean, College of Engineering and Computing

College of Engineering and Computing

Nova Southeastern University 


\section{Acknowledgements}

I send my love and appreciation to my wife, Linda, and my daughters, Jeanette and K.C., for their love and prayers during many stressful and sleepless times. They have been supportive of me throughout this process and have reminded me often that Jesus is faithful and God will make the works of my hand prosper.

I must thank Dr. Trudy Abramson for her patience and excellent guidance from the initial concept and idea paper all the way to the completion of this dissertation. Her steady hand ensured a quality final product and I cannot thank her enough.

My thanks and appreciation also goes out to my committee members, Dr. Marti Snyder and Dr. Cordelia Twomey. Your wise suggestions and sage advice ensured the process was well formed and the end product was grounded and beneficial.

To my classmates in the Computing Technology in Education doctoral program, I want to thank you all for your advice and support. At the times when it seemed the completion of the dissertation was far from certain, you were always there to say the right word to give me confidence. I appreciate it more than you know.

Finally, I appreciate everything Florida teachers and administrators did for me. They have helped from pretesting my surveys to giving me their time for this study. They provided thoughtful answers to the survey questions and I truly appreciate all the feedback. I hope that the results of this study can help you perform what I believe is one of the most important jobs in the world. 
An Abstract of a Dissertation Submitted to Nova Southeastern University

In Partial Fulfillment of the Requirements for the Degree of Doctor of Philosophy

\section{Assistive Technology Instruction in Teacher Professional Development}

by

David N. Schaaf

October 2016

Teachers who work with exceptional students have a critical responsibility to ensure these students receive the best possible education. A major part of the students' education is the implementation of assistive technology in the classroom. Unfortunately, many teachers begin their career with limited knowledge of assistive technology. Therefore, they are dependent on building their knowledge base from other sources. The results of an assessment of one source, professional development courses, are reported.

To assess the effectiveness of the professional development program, a comprehensive prescription was developed to identify gaps in the course objectives and make recommendations to improve the program. This prescription was made up of a needs assessment from Exceptional Student Education (ESE) teachers, task analysis to define necessary objectives for professional development courses, and a gap analysis of existing courses as compared to the proposed objectives.

The focus of this assessment was the professional development program of a Central Florida school district. The program was found to support some of the requirements of the district's teachers but also found areas in which the teachers needed additional support from the district. The recommendations were presented to subject matter experts within the district and the state of Florida. 


\section{Table of Contents}
Abstract iii
List of Tables viii
List of Figures ix

\section{Chapters}

\section{Introduction 1}

Background 1

Problem Statement 3

Dissertation Goal 4

Research Questions 4

Barriers and Issues 5

Assumptions, Limitations, and Delimitations 5

Definitions and Acronyms 6

Organization of the Study 8

\section{Literature Review 9}

Current Legislation 9

Assistive Technology 10

Professional Development 11

Florida Teacher Certification 12

Assistive Technology 13

Assistive Technology Applications 15

Communications 15

Reading 16

Mathematics 18

Writing 20

Universal Design for Learning 21

Teacher Responsibilities 23

Assistive Technology Barriers 25

Current Professional Development Curriculum 27

Teacher Certification Requirements 27

Summary 29

\section{Methodology 31}

Overview 31

Research Design 32

Instrumentation 33

Approach 35

Needs Assessment 36

Task Analysis 39

Gap Analysis 41

Resources 42 
Summary 42

\section{Results 44}

Needs Assessment 45

Sample Selection 45

Initial Data 47

Ranking of Limitations 49

Ranking of Resources 52

Consensus 55

Task Analysis 55

Topic Analysis 55

Procedural Analysis 57

Required Instructional Objectives 57

Gap Analysis 58

Coding of Professional Development Objectives 59

List of Professional Development Courses 60

Gap Matrix 60

Reporting 61

Summary of Results 62

\section{Conclusions, Implications, Recommendations, and Summary 63}

Conclusions 63

Research Question One 63

Research Question Two 64

Research Question Three 64

Research Question Four 65

Implications 65

Recommendations 67

Summary 69

\section{Appendices}

A. Demographic Survey 74

B. Delphi Round One Survey 75

C. Analysis of First Round Survey 76

Teacher Comments and Coding 76

D. Delphi Round Two Survey 81

E. Analysis of Second Round Survey 84

Second Round Ranking 84

F. Delphi Round Three Survey 84

G. Analysis of Third Round Survey 92

Third Round Ranking 92

Division of Limitations into Quartiles 92

H. Task Analysis 94

Topic Analysis 94

Clustering of Essential Knowledge, Tasks, and Attitudes 94 
I. Gap Analysis Matrix 97

J. Nova Southeastern University IRB Protocol 99

References 101 


\section{List of Tables}

\section{Tables}

1. ESE Teacher Gender Ratio 46

2. Identified Limitations Affecting AT Implementation 48

3. Identified Resources Which Overcame Limitations 48

4. Limitation Value Points 51

5. Limitation Value Points with Knowledge Categories Removed 52

6. Resource Value Points 53

7. Resource Value Points with Hands-on use of AT Categories Combined 54

8. Training Objectives Derived from Task Analysis 58

9. Master In-service Plan Search Terms Related to Derived Instructional Objectives 59 


\section{List of Figures}

\section{Figures}

1. Grade Level Coverage of Participants and Volunteers 47 


\section{Chapter 1}

\section{Introduction}

\section{Background}

For 40 years the education of children with special needs has been a topic of discussion among education professionals. Beginning with the Education for All Handicapped Children Act of 1975 , educators have been directed to provide students with special needs an education commensurate with students who have no disabilities. In 1990 this legislation was renamed as the Individuals with Disabilities Education Act (IDEA) with the most recent amendment signed in 2004 (https://www2.ed.gov/about/offices/list/osers/idea35/history/idea-35-history.pdf).

Based upon IDEA (2004), teacher preparation programs have sought to train teachers to ensure students with special needs receive the quality of education required by law. IDEA requires teachers to consider whether assistive technology (AT) devices or services are warranted for students with special needs to increase their access to education.

Florida lawmakers confirmed the State's desire to meet the requirements of IDEA. The Florida K-20 Education Code requires Florida schools to effectively educate students with special needs (Fla. Stat. $§ 1003.571)$. These students are known as exceptional students (Fla. Stat. $§ 1003.01)$. Florida schools are also required to provide the appropriate AT devices or services for exceptional students throughout their education (Fla. Stat. § 1003.575). 
Many Institutions of Higher Education (IHEs) provide training on exceptional student education (ESE) as part of their pre-service teacher curriculum. Unfortunately, teachers are still not adequately prepared to use AT once they graduate. Bausch and Ault (2009) studied how well pre-service preparation programs and graduate programs prepared teachers to use AT. They found that a majority of the IHEs had a limited number or no AT devices available for training.

Smith and Kennedy (2014) identified that the lack of technology training puts the onus on individual school districts to provide professional development for their teachers to fill this knowledge gap and provide the skills necessary for certifications. In an effort to ensure Florida teachers receive the requisite training, Florida lawmakers passed the School Community Professional Development Act. This law established a coordinated system for the professional development of Florida teachers (Fla. Stat. $§ 1012.98(1)$ ). Each school district is responsible for the professional development of its teachers (Fla. Stat. $§ 1012.98(4)(b)$ ). Professional development must prepare teachers to implement AT and become certified in their field of expertise (Fla. Stat. $§ 1012.56(8)(b)(5))$.

The State of Florida requires its teachers to be certified in their field (Fla. Stat. $\S$ 1012.55(1)(b)). Teachers must demonstrate mastery of general and subject area knowledge in order to be certified (Fla. Stat. $§ 1012.56(2)$ ). The certification process provides evidence that teachers are qualified to protect the educational interests of the students and their parents. The Florida Department of Education (FLDOE) issues the certificates to qualified educational professionals (Fla. Admin. Code R. 6A-4.001, 2001). Teachers can take a written examination to provide this evidence for certification. They must demonstrate mastery of competencies based upon the Competencies and Skills Required for Teacher Certification in Florida (Fla. Admin. Code R. 6A-4.0021, 2001). 


\section{Problem Statement}

Federal and state laws require Florida teachers to understand the special needs of their students and provide the best possible education for them. However, Florida teachers complete their pre-service education without the requisite skills to implement AT when they enter the classroom.

Gilakjani, Leong, and Ismail (2013) reported inadequate training is the main barrier to the teachers' use of technology following their pre-service education. Many IHEs possessed a limited number of AT devices for training or they had no AT at all (Bausch \& Ault, 2012). Additionally, teachers are overwhelmed by the amount of information they are given during their pre-service education (Smith \& Tyler, 2011).

Van Laarhoven, Munk, Chandler, Zurita, and Lynch (2012) confirmed a lack of AT resources in pre-service education. Additionally, they note there is limited space in the curriculum to add new AT content. Some pre-service technology education courses do not even require technology use during field work prior to graduation (Teclehaimanot, Mentzer, \& Hickman, 2011). As a result, Florida teachers are dependent upon professional development to prepare them to effectively use AT to teach exceptional students and to pursue certification.

FLDOE requires school districts to continuously evaluate their professional development programs to identify gaps in performance. The districts must ensure their professional development covers "the use of digital devices to supplement the delivery of curricular content to students” (Fla. Stat. § 1012.98 (7)(b)). 


\section{Dissertation Goal}

Case study methodology (Yin, 2014) was used to evaluate the professional development program of a Florida school district. The goal was to provide a comprehensive prescription to review this program and suggest changes so that it met the AT knowledge and skills of teachers.

The evaluation used the Delphi method (Dalkey \& Helmer, 1963) to identify the knowledge and skills required by Florida teachers to use AT in the classroom. District ESE teachers were surveyed to identify the main barriers they faced when using AT in the classroom and how they overcame these barriers. Competencies for AT and ESE certification were also collected from FLDOE websites to confirm the list of needs relevant to the district teachers.

Task analysis (Morrison, Ross, Kalman, \& Kemp, 2011) was used to derive the instructional objectives based upon the needs of the teachers. Goals and objectives from existing professional development courses related to AT and ESE were collected from the district Master In-service Plan (MIP). The gaps between the training needs of the teachers and the existing program were reported. The results were an assessment of a professional development program's ability to train ESE teachers in the use of AT.

\section{Research Questions}

At the conclusion of the assessment, the following research questions were answered:

1) What barriers have been reported to the effective use of assistive technology in the classroom?

2) What are the most critical training needs of Florida ESE teachers?

3) How well do existing professional development courses help teachers overcome barriers to implementing AT in the classroom or pursuing certification? 
4) How can a district's professional development curriculum be improved to meet the current needs of its teachers?

\section{Barriers and Issues}

Teacher needs data were gathered using the Delphi method (Dalkey \& Helmer, 1963). The Delphi method requires a sample size of approximately 10-20 respondents if the sample is homogeneous (Sitlington \& Coetzer, 2015). A broad representation of teachers from multiple grade levels was desired. Care was taken to keep the sample size manageable and still have teachers representing grade levels from PK through 12th grade.

Data on the professional development courses were gathered through document and website searches. Some data on the website were dated so additional information from district administrators or coordinators was required.

A critical element of a Delphi study is anonymity (Hsu \& Sandford, 2007). This was difficult in a small school; however, every effort was made to ensure the data were not attributed to specific individuals.

\section{Assumptions, Limitations, and Delimitations}

This study reported on the current state of professional development within the State of Florida. Attempting to research all 67 school districts would be a daunting task. Therefore, only one district was randomly selected. This school district is a medium-size district and maintains its own professional development program. The district's professional development program was examined and assessed on how well it met the needs of the teachers to use AT in the classroom or receive ESE certification.

Professional development curriculum was not developed for the school district. However, recommendations were provided to enhance the knowledge and expertise of the teachers. The 
recommendations identified were a result of perceived gaps between the needs of the teachers and the goals and objectives of the existing professional development courses.

\section{Definitions and Acronyms}

Alternative and Augmentative Communication (AAC) - assistive technology which aids communication for individuals who cannot talk (Dell, Newton, \& Petroff, 2012)

AT (Assistive Technology) - "any item, piece of equipment, or product system, whether acquired commercially off the shelf, modified, or customized, that is used to increase, maintain, or improve functional capabilities of a child with a disability" (20 U.S.C. § 1401(1)(A), 2006)

BEESS (Bureau of Exceptional Education and Student Services) - a Florida Department of Education organization which provides support to the state's ESE teachers

D/HH (Deaf / Hard of Hearing)

Delphi Method - an experiment conducted by the RAND Corporation whose object was to obtain a reliable opinion consensus of a group of experts using a series of intensive questionnaires interspersed with controlled opinion feedback (Dalkey \& Helmer, 1963)

Exceptional Student - any student who is gifted, has a disability, or an impairment which impacts his education (Fla. Stat. § 1003.01)

ESE (Exceptional Student Education)

ESE Center School - a Florida school designed specifically to meet the needs of students with disabilities and only has students with disabilities in attendance (Fla. Admin. Code R. 6A$1.099828,2001)$

FAC (Florida Administrative Code)

FLDOE (Florida Department of Education)

FDLRS (Florida Diagnostic and Learning Resources System) 
IEP (Individualized Education Plan) - a planning document developed for a single student within the school district who has a disability or impairment which impacts his education

IEP Team - individuals responsible for the creation and maintenance of the IEP made up of, at a minimum, the student's parents, a special education teacher, and a school district representative (Fla. Admin. Code R. 6A-6.03028, 2014)

IDEA (Individuals with Disabilities Education Act) - formerly the All Handicapped Children's Act of 1975, this federal legislation describes the need for children with special needs to receive an education commensurate with children without disabilities (20 U.S.C. § 1400)

IHE (Institution of Higher Education)

MIP (Master In-service Plan) - Florida school district document which details the professional development system for that district and the course offerings available for its inservice teachers (Fla. Stat. § 1012.98(4)(b)4.)

MTSS (Multi-Tiered System of Supports) - Florida's Response to Intervention program which provides high quality instruction and intervention matched to student needs using learning rate over time and level of performance to inform instructional decisions (FLDOE, 2008)

PDA (Professional Development Alternatives) - statewide online professional development courses available to all Florida teachers

PLC (Professional Learning Community) - a group of faculty who regularly meet to study more effective learning and teaching practices (FLDOE, 2010)

UDL (Universal Design for Learning) - making curriculum "accessible and appropriate for individuals in different background, learning styles, abilities, and disabilities" (Rose \& Meyer, 2002)

USDOE (United States Department of Education) 


\section{Organization of the Study}

The next chapter reviewed the current state of teacher education related to AT and ESE. It identified the limitations of pre-service education and the recommendations to teacher education from these studies. The chapter also described professional development and certification opportunities in the State of Florida.

The third chapter described the single case study methodology as well as the plans to collect and analyze data on teacher needs. Multiple sources of data were described to include the use of the Delphi method to collect and prioritize the critical needs of teachers. Finally, the evaluation process to identify gaps between the needs of the teachers and the professional development course objectives was discussed.

The fourth chapter presented the data collected and the results of the analysis of these data. The most critical training needs of teachers were identified as well as the instructional objectives which were required to meet these needs. The instructional objectives were compared to the objectives of the existing courses to highlight any gaps to be addressed.

The final chapter examined the conclusions and implications of this case study. The recommendations to improve the district's professional development program were also described. However, the recommendations were not limited to professional development. Recommendations for ad hoc training were also discussed to meet the immediate needs of the teachers which could not wait until the required courses are offered. The process used to report the conclusions and recommendations was then explained. Finally, a summary of this study was presented. 


\section{Chapter 2}

\section{Literature Review}

The literature review begins with the foundational legislation requiring teachers to ensure their special needs students receive an education commensurate with students who do not have disabilities. The legislation focuses on the teachers' requirement to use assistive technology (AT), the requirement for teacher professional development, and the competencies teachers must possess to become certified in their areas of expertise.

The definition and classroom applications of AT in the areas of communications, reading, mathematics, and writing are introduced. The concept of Universal Design for Learning (UDL) is described as it highlights the fact AT provided for students with special needs can be utilized to positively impact the education of all students regardless of their level of disability.

Barriers to the effective utilization of AT are discussed related to limitations of preservice education. The focus then changes to how in-service education, specifically professional development, can address the lack of effective AT training at the pre-service level. Elements of a professional development program maintained by a Florida district and Florida's teacher certification program will be described to create a basis for possible recommendations.

\section{Current Legislation}

Florida teachers are held to the standards set forward by federal and state law. They must adhere to the requirements identified by the state of Florida for teaching students with special 
needs, which is also called exceptional student education (ESE). The specific legislation discussed below includes the planning for AT to support exceptional students, the state and district professional development programs, and Florida's requirements for teacher certification. Assistive Technology

The Individuals with Disabilities Education Act (IDEA) of 2004 requires teachers who have students with special needs in their classrooms to consider whether AT devices or services are warranted for individual students to increase their access to education (20 U.S.C. $\S$ 1401(1)(A), 2006). This act defines assistive technology as "any item, piece of equipment, or product system, whether acquired commercially off the shelf, modified, or customized, that is used to increase, maintain, or improve functional capabilities of a child with a disability" (20 U.S.C. $§ 1401(1)(A), 2006)$. Each student with special needs must also have an Individualized Education Plan (IEP) which documents the specific needs, sets measurable annual goals, and identifies accommodations required for the student (Fla. Admin. Code R. 6A-6.03028, 2014).

The IEP is developed and maintained by a team consisting of the student's parents, at least one special education teacher, and a representative of the local educational agency. If the student spends part or all of the day in a general education classroom, at least one general education teacher must also be a member of the team (20 U.S.C. $\S 1414(d)(1)(B), 2006)$.

The IEP team is responsible for reviewing the needs of the student and determining what support is needed to include the use of AT. A team member must be able to interpret the student's evaluation results and explain its instructional implications to the rest of the team. It is acceptable if one of the above team members can perform this evaluation, otherwise another individual should be assigned to the team for this purpose (20 U.S.C. $§ 1414(d)(1)(B), 2006)$. 
As each student's disability is unique and can impact his education differently, it may be deemed necessary to include individuals with specific knowledge of the disability in question. Dell, Newton, and Petroff (2012) recommended including an occupational therapist, a physical therapist, or a speech-language pathologist depending on the needs of the student. The IEP team is also responsible for identifying any AT devices or services to be used to support the student (20 U.S.C. § 1414(d)(3)(B)(v), 2006). To address the AT requirements, an AT specialist should also be assigned as a member of the IEP team.

\section{Professional Development}

The dearth of AT training during the pre-service education negatively impacts a teacher's ability to implement the recommendations of the IEP team. It also places a critical requirement on school districts to provide adequate technology training to their in-service teachers. However, many school districts do not have the resources to develop and implement professional development courses for implementation of technology (Smith \& Kennedy, 2014).

Florida Department of Education (FLDOE) provides assistance to all Florida districts and their teachers through its Bureau of Exceptional Education and Student Services (BEESS). BEESS publishes a list of resources available to its teachers to support ESE. A particular training resource identified by this publication is a set of online professional development courses directly related to ESE. These courses are called Professional Development Alternatives (PDA) (FLDOE, 2011).

In addition to the state's professional development offerings, each Florida school district is also responsible for maintaining a Master In-service Plan (MIP) which details their approach to professional development for their in-service teachers (Fla. Stat. § 1012.98(4)(b)4.). The MIP provides responsibilities of the school district and its teachers. Florida school districts have also 
been tasked to develop annual digital classroom plans (Fla. Stat. § 1011.62(12)(b)). These documents contain the districts' professional development courses available to their teachers and the courses' objectives. The state's professional development courses are also listed as training resources in the districts' planning documents.

Technology in professional development courses is not limited to content. FLDOE requires districts to utilize distance learning and other technologies in the delivery of professional development (Fla. Stat. § 1012.98 (4)(b)(8)). This technology can be used to demonstrate and model strategies or techniques to teachers. Additionally, this technology can be used to assist teachers in "implementing, practicing, and reflecting on what they have learned and evaluating the effectiveness of that learning" (FLDOE, 2012, p.65).

FLDOE created a professional development system evaluation protocol for its districts. This evaluation protocol is used to ensure the best quality of professional development throughout the State of Florida and to provide districts with the methods to conduct on-going assessments of their programs (FLDOE, 2010). Reviewers are trained to look at how technology is used in professional development where the technology itself is not being trained. Reviewers should also examine if technology is used to allow in-service teachers to share their experiences and information on techniques they have learned and implemented. Finally, the reviewer should look at the effectiveness of the technology to allow the teachers to follow-up with their instructor or peers after the completion of the course (FLDOE, 2012).

\section{Florida Teacher Certification}

FLDOE implemented a certification program to ensure Florida educators are qualified in their field. Teachers who are certified must "possess adequate pedagogical and relevant subject 
matter knowledge and demonstrate an acceptable level of professional performance" (Fla. Admin. Code R. 6A-4.001, 2001).

The Florida Legislature established the certification requirements for educational personnel in Florida public schools. These requirements assure that educational personnel have the appropriate skills in reading, writing, and mathematics, as well as adequate pedagogical knowledge to enhance student learning. Educational personnel must demonstrate relevant subject matter competency in various areas, to include technology, in order to achieve an acceptable level of professional performance (Fla. Stat. § 1012.56).

All educational personnel should hold a certification based upon their position. This also applies to teachers in the virtual and blended learning environments (Fla. Stat. § 1012.55). Earning a certificate requires the personnel to demonstrate a mastery of the subject area. FLDOE and the various school districts provide competency-based professional development to aid teachers in receiving certification (Fla. Stat. § 1012.56).

The certification process provides evidence that educational personnel are qualified to teach in the State of Florida. This process also ensures a mechanism to protect the educational interests of the students and their parents. FLDOE issues the certificates to qualified educational professionals (Fla. Admin. Code R. 6A-4.001 2001).

\section{Assistive Technology}

Dell et al. (2012) identified elements of AT based upon their level of technology. Lowtech AT includes a pencil grip to assist in holding a pencil, a dowel rod to use a computer keyboard, a paper with cutouts to focus on a single line of text, or a piece of wood with pictures pasted on it so the student can point to an item to communicate. High-tech AT includes PCs, tablets, smart phones, alternative and augmentative communication (AAC), and educational 
software and applications. Some educational software tools may be purchased, but features such as an on-screen keyboard and screen magnifier are usually included in most operating systems. Mid-tech AT is electronic but is not as expensive as high-tech devices. These devices include large-button calculators or digital recorders.

Each disability creates unique challenges. Teachers must understand each student's needs and identify potential AT which will work for that student. The teacher must also evaluate the effectiveness of the AT and be willing to try other AT devices if the student does not respond positively. Persistence is the key to finding the right AT device for a student (Brownell \& Leko, 2014). Organizations which provide lending sites provide an excellent opportunity to try out new equipment and evaluate its effectiveness prior to purchase (Moody, 2015).

The National Center on Accessible Instructional Material has an online tool which helps teachers and IEP teams decide if AT is beneficial, what tools or devices to investigate, and recommendations on sources and training for the device or service (Dell et al., 2012). Another source of AT for Florida teachers is the AT and Universal Design for Learning (UDL) Loan Library located at the University of South Florida (http://www.at-udl.net/). The AT \& UDL Loan Library was created as a part of Florida's Multi-Tiered System of Supports (MTSS). It helps all Florida school districts by providing AT devices and software so teachers can evaluate them before purchase for use in the classroom.

Communication is key to ensure effective implementation of AT. Teachers are expected to work together with a team to prepare IEPs for their students. Teachers also need to be able to utilize the technology recommended by the IEP team. 


\section{Assistive Technology Applications}

Students with special needs have unique communication requirements. Additionally, various subjects require specialized AT. The following sections examine how AT can impact the communication needs of students as well as which AT devices and services can enhance the reading, mathematics, and writing curricula.

\section{Communications}

When a child is diagnosed as Deaf or Hard of Hearing (D/HH), the parents must decide the child's primary mode of communication: sign language or spoken language. As this is a very personal decision for the family, a teacher could potentially have two D/HH students, one who signs and one who speaks. The teacher must be familiar with both communication methods. If the teacher does not understand sign language, an interpreter must be present for the student who signs. The teacher must understand hearing technology as well (Nelson, Lenihan, \& White, 2014).

The hearing aid is the most commonly used device for D/HH students who speak. However, the use of hearing aids requires some residual hearing. For students with little or no residual hearing a cochlear implant may be used. The teacher must be familiar with the basic components, features, and operation of both hearing aids and cochlear devices. Additionally, the hearing devices could malfunction for up to one-half of the students in the classroom. The teacher must be able to perform troubleshooting procedures to determine if the problem can be fixed easily or if repairs are required (Nelson et al., 2014).

Schaaf (2013) monitored a D/HH classroom and identified AT used to support D/HH students in the classroom. The teacher utilized a sound field amplification system and an interactive whiteboard. The amplification system allowed the teacher to increase the volume of 
her voice. The interactive whiteboard allowed the teacher to display curriculum and write notes on the whiteboard.

Computers are also delivered with various AT devices to support students with special needs. Many of these functions support students with visual impairments, such as screen magnification, increasing the size of the mouse pointer, and the ability to convert text to speech. Visual cues, such as flashing icons, can augment audio cues to alert D/HH students to issues (Dell et al., 2012).

Physical impairments can also impact a student's ability to communicate. AAC technology provides critical support to these students who cannot speak. Tools can be as simple as a board with pictures pasted on it. The student can point to the picture to tell the teacher what he wants. A switch can also be used so the student can select options if he has limited movement. High tech AAC includes systems which have a large vocabulary allowing the student to speak in full sentences. The student can display the text on a screen or have the device speak for him (Dell et al., 2012).

The teacher must take time to ensure that the specific vocabulary for the subject is in the AAC tool. If the correct vocabulary is not loaded the student will not be able to participate in the lesson. The teacher may load the vocabulary herself or provide it to a staff member to load on the tool. The teacher may also be dependent on a staff member to provide initial troubleshooting assistance on the tool or on the school's network (Dell et al., 2012).

\section{Reading}

Reading can be difficult for students with special needs. Rose and Dalton (2009) posit that learning to read using a digital format can provide a level of individualized instruction which is not possible with printed text. Using a magnifying glass to read a book helps, but allowing the 
students to adjust the screen magnification to their personal desires can also raise the students' engagement.

Bouck, Flanagan, Heutsche, Okolo, and Englert (2011) took the digital format to the next level. They studied the results of a four-year implementation of AT as it relates to social studies instruction. Social studies courses require reading comprehension; however, some students with special needs may not be able to understand many of the concepts they are reading. The authors interviewed 13 teachers who implemented the Virtual History Museum (VHM) to teach social studies to their students.

The teachers acted as curators in the VHM and selected various artifacts, such as documents, images, or videos for the students to review. To provide background information, the teachers created text based upon the reading ability of the students or a narrative to which the students listened. At the end of the course the students analyzed the information they gathered and produced a product, such as a paper, journal entry, or a diagram.

The teachers found the VHM to be a great tool to help the students with special needs access the material. Unfortunately, the teachers also highlighted the amount of work required to set up and maintain the museum. They received help initially with the technology and were given time to focus on the tool, but the amount of support waned during the project. By the end of the project, the administration's support of the program tapered off. Only two teachers continued to use the VHM after the initial test.

Although the teachers found VHM to be useful, they reported its use was limited. Once the supports were removed, the teachers were no longer able to use the system effectively. They did not have the time to update the virtual museum. Also, the teachers did not have the technical 
training to maintain the software. In the end, the potential of VHM was not realized (Bouck, et al., 2011).

Blind or visually impaired students may possess reading comprehension skills but still need an accommodation to help them access the reading materials. Some AT devices scan in the text from a book or article, convert it to electronic text, and then read it aloud to the student. Document software and E-book readers may also provide accessibility to blind and visually impaired students by reading text aloud. To be fully effective for blind students, the devices must have easily memorized function keys which can be used without looking at the keyboard or screen (Dell et al., 2012).

\section{Mathematics}

Research in the use of AT in the field of mathematics is somewhat lacking. Bouck and Joshi (2012) found only 17 articles on AT in mathematics education. In order to learn about this subject, they reviewed the surveys from 154 middle school special education teachers to identify the AT the teachers used to teach mathematics as well as its effectiveness. The teachers were also asked to specify factors which encouraged the use of AT and which hindered its use.

Boush and Joshi (2012) presented the teachers with 11 tools made up of calculators, manipulatives, web-based instruction, and software. The teachers reported they mainly used a standard four-function calculator and concrete manipulatives. Concrete manipulatives are "physical objects students can manipulate to explore and develop an understanding of a mathematical concept" (Bouck \& Flanagan, 2010, p. 186).

Manipulatives can also be interactive, web-based representations called virtual manipulatives. Bouck and Joshi (2012) found over 70 percent of the teachers who were surveyed never used virtual manipulatives. The main reasons for the lack of use ranged from not having 
computers in the classroom due to funding constraints to not having the time to learn how virtual manipulatives worked and how they could be beneficial.

Moyer-Packenham, Salkind, and Bolyard (2008) found that if teachers had the time to learn about virtual manipulatives, they could use the virtual manipulatives to help students better understand abstract mathematic concepts. Their study began by having 116 teachers from kindergarten through 8th grade attend a one-week mathematics professional development program during the summer, including training on the use of virtual manipulatives. Additionally, the teachers met in four formal meetings during the following fall and spring. The goal of this training was to enhance the teachers' mathematics instruction.

The teachers then used this knowledge to develop lesson plans. They were encouraged to use virtual manipulatives in at least one of their lessons. The authors reviewed the lesson plans and found 45 percent of the teachers used virtual manipulatives to help the students during investigation and 37 percent of the teachers used the virtual manipulatives for skill solidification. The teachers were not likely to use the virtual manipulatives to introduce a lesson or as a part of a game, however.

Fifty-two percent of the teachers used only virtual manipulatives in their lesson plans while $41 \%$ of the teachers used physical manipulatives followed by virtual manipulatives. Moyer-Packenham, Salkind, and Bolyard (2008) concluded the teachers used virtual manipulatives "when they were central to the lesson and to the learning and development of the mathematics in the lesson" (p. 215).

O’Malley, Jenkins, Wesley, Donehower, Rabuck, and Lewis (2013) studied the use of iPads to teach mathematics. They used single-case research methodology with the ABAB design. They studied students performing mathematical operations using paper and pencil, then the iPad, 
returning to paper and pencil, and finally the iPad again. The teachers found the students to be more engaged when using the iPad. In fact, the students were disappointed when they returned to paper and pencil. The teachers also felt the students made better progress when using the iPads than with paper and pencil.

The benefits were tempered by the barriers encountered. The teachers required additional training to effectively teach with the iPads. Similarly, teachers who expressed limited confidence in the use of technology tended to not use the iPads as much. Another barrier is the amount of support students needed to use the iPads. Even though many of the students had access to technology at home, they were not able to use technology in the classroom without assistance. Many parents reported the technology used at home was more for entertainment purposes and not educational. The final barrier was the amount of time required to use, store, and maintain the iPads. The teachers spent more time than expected supporting the use of the iPads (O'Malley, Jenkins, Wesley, Donehower, Rabuck, \& Lewis, 2013).

\section{Writing}

When contemplating the use of AT to help students write, the first thing which comes to mind is the physical part of writing using a writing implement or a computer. However, the process of writing starts well before any words are written or typed. The process begins with planning. During the planning phase the student develops the initial idea for the paper. Students with special needs may have difficulty concentrating or coming up with an idea. Teachers may provide a graphic organizer or format template to help the student order their thoughts prior to writing (Dell et al., 2012).

The next phase is to start drafting the paper. This is the physical part of writing. Regardless of the medium, students with special needs may have difficulty performing this 
action. Teachers can provide a tool to help the student hold a pencil or a dowel to use the keyboard of the computer. Additionally, a student can use speech recognition software to draft his paper (Dell et al., 2012).

The third and fourth phases of the writing process are reviewing and editing the paper. Text-to-speech software can be used to help the student review the paper. A word processor can also be used to make modifications easier. Some applications include word prediction software so the student can type in part of a word and then select the word they desire. These applications also have an auto correct function to reduce misspelled words (Dell et al., 2012).

Unfortunately, simply using AT to assist in the writing process will not ensure success. The teacher must ensure the AT is appropriate for the student. Students who are weak in writing may not benefit from speech recognition. Additionally, speech recognition software requires a quiet environment for accurate recognition of words. Students who have difficulty speaking may not be able to use speech recognition software. Poor spellers may not be able to type in the word correctly enough and the predicted words presented to the student would not include the desired word (Dell et al., 2012).

\section{Universal Design for Learning}

AT systems are usually designed for specific disabilities; however, many of the AT devices used in the classroom could benefit other students. Utilizing technology to support multiple students, regardless of disabilities, is the main tenet of Universal Design for Learning (UDL) (Schaaf, 2013). For example, an electronic whiteboard can be used in a general classroom to improve communication with all students. The teacher must understand when technology is used as an accommodation to a disability or when it is implemented to assist all students in the classroom. 
Burgstahler (2011) differentiates between accommodations made for students with special needs and the use of UDL in the classroom. An accommodation is a reactive approach to providing access for students. UDL is a proactive approach to address the needs of all students. Employing UDL tools in the classroom will not eliminate the need for specific accommodations, but it may save time when students with special needs are in the classroom.

Messinger-Willman and Marino (2010) identified differences between AT and UDL. Both AT and UDL rely on technology to improve the education of students with special needs. AT is individual specific and seeks solutions that take into account a student's strengths and weaknesses. UDL focuses on a holistic approach to curriculum development. Teachers create flexible instruction, engagement, and assessment options that reduce barriers at the outset of the learning process.

UDL is based upon the concept of universal design in architecture. Federal law requires buildings to be built to enhance accessibility for individuals with disabilities. As a result, existing buildings were modified to add ramps, elevators, and escalators. In addition, sidewalks had cutouts installed for wheelchairs. Making changes to existing infrastructure can be expensive so architects started adding accessibility to their designs. Soon after these accessibility features were added it became obvious that individuals without disabilities also benefited from this design. For example, parents could use sidewalk cutouts for their strollers (Rose \& Meyer, 2002).

UDL is composed of three principles: how the material is presented, how students demonstrate their knowledge to the teacher, and how the student is engaged (Rose \& Meyer, 2002). First, presentation of the material is critical to specific disabilities. Students with visual 
impairments require verbal or tactile presentation while $\mathrm{D} / \mathrm{HH}$ students need visual presentation (Dell, et al., 2012).

Second, teachers must decide how to best have students demonstrate their knowledge. Students can write reports, but students with limited writing skills may be allowed to use pictures or drawings to explain a concept. Some students may need to verbally express themselves (Dell, et al., 2012).

Finally, all students must be engaged in the education process. The teacher can provide multiple media resources to meet the needs of various students. In some cases the teacher may have a student read a book. The teacher may also provide an audio book for those students who cannot read. Regardless of the UDL principle, the teacher must determine the best method to address the diverse needs of all students (Dell, et al., 2012).

\section{Teacher Responsibilities}

Special education teachers are required to be a member of the IEP team for each student with special needs in their classroom (20 U.S.C. $§ 1414(d)(1)(B))$. If the student is in a general education classroom, the general education teacher must also be a member of the IEP team. Although the IEP team considers whether the child needs assistive technology, the teacher should also be knowledgeable to recommend AT. Regardless, the teacher is responsible for implementing the team's recommendations.

Each student is unique and therefore has different needs. The IEP team must identify the proper AT based upon the specific needs of the student. Unfortunately, if the teacher is not knowledgeable about AT, he may not provide any recommendations for AT. If the AT is not identified in the IEP it may not be integrated effectively in the classroom. However, simply 
identifying the proper AT does not guarantee its effectiveness. The teacher must also be fully trained in its use and how to implement it correctly (Smith \& Kennedy, 2014).

Van Laarhoven and Conderman (2011) identified the responsibilities of teachers who have students with special needs in the classroom. Teachers must be able to evaluate the students to determine their specific needs in the classroom. With this information the teacher can match students to the most appropriate AT. Once the AT devices or services have been identified, the teacher should consult and collaborate with other professionals regarding a student's AT to gain knowledge in the best practices. If the AT device or service is not used correctly, the educational goals identified in the IEP will not be achieved (Coleman, 2011).

The teacher should then implement the specified AT in the classroom and train the student and his family to use AT when the student is not in the classroom. Unfortunately, 75 percent of students and their families have never received AT training (Coleman, 2011).

To ensure the AT works as desired, the teacher must adapt and modify curriculum to effectively incorporate the AT devices and services. Technology changes constantly; therefore, the teacher must also be able to evaluate new and updated AT devices and services, identifying when new AT should be implemented to support students. Any recommended changes must be coordinated with the IEP team.

Bausch and Ault (2012) listed professional competencies required by special education teachers. These teachers are expected to have knowledge of AAC strategies. Special educators also should be able to plan and manage the use of technology in the classroom for students with special needs and use technology to conduct assessments. 


\section{Assistive Technology Barriers}

Coleman (2011) identified issues which adversely impact a teacher's ability to use AT successfully in the classroom. First, the teachers are not able to assess students' needs or identify the appropriate AT device or services. The lack of adequate training is the primary cause of this problem.

Another issue identified by Coleman (2011) is that AT, when implemented, is not timely or consistent. Failure to provide the correct AT device at the right time could be as ineffective as having no AT at all. The teacher must also be aware that the individual student has to cope with his disability. In some cases, the student may not accept that he has a disability or his culture may look down on children with disabilities. Motivation may be another issue the teacher must address.

Finally, the implementation of AT in the classroom could also be adversely impacted by space limitations, Internet access, portability, or access to electrical outlets. Each of these issues must be addressed, but a teacher who has not been adequately trained will be at a severe disadvantage.

Sze (2008) identified cost, obsolescence, training, support, and maintenance as critical barriers to the integration of technology in the classroom. These issues, although impacting the classroom, fall into the realm of school administration. Teachers must have a consistent support network within their school regarding the use of AT. The school must develop policies related to its use and support of AT.

Messinger-Willman and Marino (2010) identified barriers which stem from a lack of professional development opportunities. Many secondary teachers have limited time to explore, experiment, and study AT and UDL integration. Professional development attempts to include 
too much information during a limited amount of time. Professional development must be designed to provide more focus on AT and UDL.

AT is not a panacea for students with special needs. Teachers must have the training and resources to effectively implement AT in the classroom. Many researchers have identified the teachers' lack of AT skills and knowledge as a problem. As a result, they have published many recommendations and best practices which can be implemented in pre-service education to correct the problem, such as encouraging pre-service teachers to use technology in their private lives to gain experience in the benefits of technology (Gilakjani, Leong, \& Ismail, 2013).

Gilakjani et al. (2013) reported inadequate training as the main obstacle to the use of technology by teachers following their pre-service education. Many IHEs possess a limited number of AT devices for training or they had no AT at all (Bausch \& Ault, 2012). Additionally, teachers are overwhelmed by the amount of information they are given during the pre-service education (Smith \& Tyler, 2011).

Teclehaimanot, Mentzer, and Hickman (2011) highlighted that some pre-service technology education courses did not require technology use during student teachers' field observations. Additionally, Van Laarhoven and Conderman (2011) found that simply presenting, discussing, or showing videos of AT devices was not sufficient to train pre-service teachers. They reported that multiple hands-on experiences were needed to provide the pre-service teachers with the knowledge, confidence, and skills to use AT devices effectively.

Teachers regularly report the need for more education on AT. This indicates the importance of pre-service and professional development training (Ajuwon, Meeks, GriffinShirley, \& Okungu, 2016). However, training on AT is difficult due to the advancements of technology. Teachers should not only know current tools but they must also be aware of tools 
which are outdated and which may be in the future (Peterson-Karlan, 2015). Lastly, professional development training should include hands-on training as well as real world practical experiences (Connor \& Beard, 2015).

\section{Current Professional Development Curriculum}

Florida Department of Education (FLDOE) provides assistance to all Florida districts and their teachers through its Bureau of Exceptional Education and Student Services (BEESS). BEESS publishes a list of resources available to its teachers to support ESE. A particular training resource identified by this publication is a program called Professional Development Alternatives (PDA). This online training provides Florida teachers with opportunities to become more competent in ESE and AT (FLDOE, 2011).

FDLRS coordinates the schedule of the PDA modules for use by Florida teachers. These training modules are funded by the FLDOE and are available online. The courses are facilitated by the 19 FDLRS associate centers to make the courses available to all Florida teachers (FLDOE, 2011).

The PDA project began in 2002 to address national legislation supporting ESE and the need to increase the number of ESE teachers. Two critical elements were to reduce costs through collaboration and encourage the utilization of distance education to help districts afford professional development for their teachers (http://www.fl-pda.org/about/HistoryOfPDA.pdf). The PDA courses are listed in the district's MIP.

\section{Teacher Certification Requirements}

Florida teachers can choose from eight areas for certification: Elementary Level, Middle Level, Secondary Level, Science, Elementary and Secondary, World Language, Exceptional Student Education (ESE), and Professional Service. Four types of endorsements, or riders, also 
exist for these certification areas: Academic, Administrative, Specialty, and Vocational (Fla. Admin. Code R. 6A-4.0021 2001).

The State of Florida offers 72 certification opportunities to its teachers. The certificates range from elementary level to middle and secondary level subjects in the areas of mathematics, English, science and world languages (Fla. Admin. Code R. 6A-4.0021, 2001).

Teacher certification testing was established by the Florida Legislature in 1988. Initially, the State Board of Education identified competencies and skills for 18 certification areas. Six of these areas were related to students with special needs: Emotionally Handicapped, Mentally Handicapped, Physically Impaired, Specific Learning Disabilities, Speech-Language Impaired, and Varying Exceptionalities (FLDOE, 2014).

Additional certification areas focusing on teaching students with special needs were added later: Hearing Impaired in 1990, Visually Impaired in 1991, and Exceptional Student Education in 2002. The final change to the list of ESE certifications occurred in 2004 when the certification areas of Emotionally Handicapped, Mentally Handicapped, Physically Impaired, Specific Learning Disabilities, and Varying Exceptionalities were removed (FLDOE, 2014).

Many certifications require competencies and skills related to ESE. Four subjects fall into the ESE area: ESE, Hearing Impaired, Speech-Language Impaired, and Visually Impaired. ESE subjects are also included in the Administrative Coverages areas, such as American Sign Language, Autism Spectrum Disorders, Prekindergarten Disabilities, and Severe or Profound Disabilities. AT and accommodation competencies and skills are also required by FLDOE in order to receive numerous other certifications (FLDOE, 2014). 


\section{Summary}

In order to use AT effectively, teachers must have been introduced to various devices and services and must have developed skills and confidence in their use. Although teachers may not be experts in the use of AT, they must be able to identify when specific technology could be beneficial for their students with special needs. Teachers must also be comfortable enough with the technology to train the students and their families on the correct usage of the technology.

Teachers must ensure the AT will be effective for each student. Continuous evaluation and follow-up are required, and the teacher must be willing to try new AT devices if the current implementation is not providing the desired effects. Even though in-service teachers have not gained the knowledge and experience they need, they will still be expected to implement AT for their students with special needs. For this reason they must seek out continuing education to improve their skills.

FLDOE recommends teachers pursue certification in ESE subjects to document their knowledge. Many teachers will have students with special needs in the general education classroom so ESE certification would also be expected for these teachers. Florida professional development courses related to ESE and technology must prepare the teachers to meet the requirements for certification and to ensure teachers have the requisite knowledge to implement AT.

This literature review highlighted the fact that teachers possessed limited skills to assess students' needs and select appropriate AT for use in the classroom. Teachers were also hindered in the effective use of AT because they did not have personal experience with the AT needed for ESE. The literature review also introduced state professional development and certification opportunities for Florida teachers. This information will be used in the next chapter to describe 
the methodology used to answer the research questions and provide recommendations for improvements to professional development programs. 


\section{Chapter 3}

\section{Methodology}

\section{Overview}

Florida teachers have specific requirements placed on them when they teach exceptional students. They must have the requisite knowledge to meet these requirements. Professional development programs must be designed to meet the needs of the teachers. Case study methodology (Yin, 2014) was used to examine the current course offerings of a Florida school district, how well the district's professional development courses met the needs of the teachers, and how effectively they prepared teachers to use AT. The goal was to provide a comprehensive prescription for reviewing a professional development program and suggesting changes so that it meets the AT knowledge and skills required by its teachers.

A case study requires data from multiple sources to describe the area under study (Yin, 2014). Data were first gathered from a series of surveys conducted with in-service ESE teachers to create a needs assessment. A needs assessment is made up of four phases: planning, data collection, data analysis, and report writing (Morrison, et al., 2011). The planning phase will be discussed throughout this chapter. The other three phases will be covered in the next chapter.

During the planning phase, the target audience and strategy were defined as well as the methodology for data collection. The target audience was ESE teachers who use AT in the classroom, school administrators, and professional development coordinators. 
The strategy was to collect and analyze data in a distinct four-step process to evaluate the professional development program. First, the needs of the teachers were identified through the use of the Delphi method (Dalkey \& Melmer, 1963). This methodology uses multiple surveys in an iterative process where initial issues related to AT and ESE are identified and then teachers prioritize the issues to determine which are the most critical to them (Morrison, et al., 2011).

Second, task analysis was used to identify instructional objectives based on the knowledge required by the teachers (Morrison, et al., 2011). The knowledge requirements were determined from the results of the Delphi surveys. Third, the instructional objectives from the task analysis were compared to the district's existing professional development courses. Objectives currently covered by the existing courses were highlighted. Finally, gap analysis highlighted objectives which were not addressed in current curriculum. The final report provided the district with data for enhancing the existing professional development program.

\section{Research Design}

Case studies look at a contemporary issue in context with its surroundings as opposed to experimental studies which seek to evaluate an issue in a test environment to determine how changes to selected variables affect its overall effectiveness. Case studies are critical when the context of the issue is pertinent to the overall phenomenon. Many times the phenomenon being studied has more variables than data points. This makes the issue distinctive and requires it to be studied as a whole (Yin, 2014).

The variables related to the professional development program examined include the knowledge and skills required by Florida teachers, competencies for teacher certification, and professional development course objectives. Case study research calls for the collection of many forms of qualitative data (Creswell, 2013). The collection methods for these data include a series 
of surveys, documents, and audio-visual materials such as websites. ESE teachers were surveyed to gather information on the current state of AT usage in the classroom. FLDOE websites were examined to document the competencies teachers must attain in order to become certified. The district's MIP and FDLRS websites were used to document the goals and objectives of existing professional development courses.

Yin (2014) highlighted the need to approach case studies with sufficient rigor to ensure systemic procedures were followed and to reduce the possibility that equivocal evidence could impact the findings and recommendations. The process for surveying ESE teachers is fully defined below to allow for repeatability. The district and FLDRS professional development courses will be examined in a consistent manner to identify objectives related to AT and ESE. Likewise, all certification programs will be examined consistently to identify ESE and AT certification requirements.

\section{Instrumentation}

The prioritized list of knowledge needed by teachers was created using the Delphi method. The original Delphi method was introduced by the RAND Corporation (Dalkey \& Helmer, 1963). The results were used by the U.S Government to determine plans for the United States' security against a potential attack from the Soviet Union during the Cold War. The methodology has been adapted to various subjects over the years, including research in the area of education (Reeves \& Jauch, 1978).

The Delphi method consists of multiple rounds of surveys (Ludwig, 1994). As each round completes, the data are summarized. The round one survey contained open-ended questions to gather broad data from the teachers (Dalkey \& Helmer, 1963). Open-ended questions were used because it is difficult to identify all issues encountered by teachers when 
using AT. Open-ended questions may uncover data which are unexpected but reflect the real views of the teachers. Open-ended questions also give teachers the ability to answer the questions in their own words (Fowler, 2014). Issues identified in the literature review were included in the first round survey to spark ideas on barriers the teachers may have encountered.

Round one survey questions were assessed through the use of pilot testing (Creswell, 2013). Fowler (2014) stressed self-administered surveys require pretesting. The survey was emailed to three Florida teachers. The educational experience of these teachers ranges from 3 to 25 years in both general and special education. Two of the three teachers had at least three years experience in ESE. The third teacher worked in physical education and interacted with exceptional students in the general classroom.

Pretesting can refine the planned data collection and ensure the questioning is relevant to the subject matter (Yin, 2014). The teachers used for pretesting were asked to fill out the survey as if they were actual respondents. The teachers were asked if the instructions and questions were clear, if they understood what types of answers were expected, and whether or not they had problems answering the questions (Fowler, 2014). The data provided by the pilot testers confirmed the validity of the survey.

Following the pretest, the first survey was sent out to the 18 district teachers. The data collected during the first round were coded to create a list of specific limitations to the use of AT and resources which overcame these limitations. These lists were used to create the second round survey.

In the second round, the teachers were asked to rank order their top five limitations and resources from the lists provided in the survey (Dalkey \& Helmer, 1963). They were also asked to provide rationale for why they selected the specific issues. 
The third round survey was created once the second round data were summarized. The overall prioritization of issues and rationale was provided only to the teachers who completed the second round survey. Each teacher was also provided with her individual prioritizations and rationale from the second round (Ludwig, 1994). During the third round, the teachers reviewed their choices and were asked if they wanted to change their priorities. As in the second round, the teachers were asked to justify their prioritization (Dalkey \& Helmer, 1963).

\section{Approach}

This case study assessed the professional development program of a Florida school district in how effectively it met the needs of its ESE teachers. The district teachers were sent a series of three surveys to identify their most critical needs. The results of the final survey provided the consensus of issues encountered by the teachers. This consensus was used as input for the task analysis (Morrison, et al., 2011) to identify proposed course objectives for the professional development program to help overcome these issues.

A task analysis was conducted on the results of the needs assessment to develop core instructional objectives. The objectives were then compared to existing professional development course objectives. Gap analysis identified which course objectives were not covered in the district or FDLRS professional development curriculum. The data found through the gap analysis were listed in the recommendations to improve the district's professional development program.

Subject matter experts (SMEs) were used to validate the needs assessment and recommendations (Morrison, et al., 2011). The SMEs utilized for this research were school administrators, teachers, and technology specialists from the school and FDLRS. 


\section{Needs Assessment}

To address the challenges encountered by Florida teachers, a needs assessment was performed. The teachers surveyed for the needs assessment were from the ESE center school of a Central Florida school district. A Florida ESE center school is designed specifically to meet the needs of students with disabilities and only has students with disabilities in attendance (Fla. Admin. Code R. 6A-1.099828, 2001). This center school was an excellent source of ESE teachers. A demographic survey (Appendix A) was sent out to all teachers at this school. The data were used to determine if the sample of teachers accurately reflected the population of Florida ESE teachers.

A standard sample size for Delphi surveys has not been defined. Ludwig (1994) reported Delphi studies used samples from 10 to 50 individuals. Sitlington and Coetzer (2015) stated 10 to 20 respondents are satisfactory if the sample is homogeneous. At least ten respondents were desired to collect valid data for the needs assessment.

Data collection utilized the Delphi method to prioritize the needs of the teachers (Dalkey \& Helmer, 1963). The standard Delphi process usually consists of three rounds (Ludwig, 1994). The first research question, What barriers have been reported to the effective use of assistive technology in the classroom?, was answered by the results of the first round survey.

The first round survey (Appendix B) incorporated data from the literature review on issues teachers had encountered using AT. The survey asked open-ended questions to which seven of the teachers provided insight into the AT barriers they encountered and resources they used to overcome the barriers, a response rate to 25.9 percent. The data from the literature were meant to help the teachers understand the aim of the question, but the teachers used their own experiences to answer the questions. 
The teachers were also asked which certifications they planned to pursue in the next two to three years. Competencies from the certifications, related to ESE and AT, were collected from the FLDOE website.

The data from the first round survey were analyzed though coding to glean the issues which could be addressed by training (Fowler, 2014). Code development for open-ended questions is interactive. Categories were identified as they emerged from the survey answers (Appendix C). Answers which were similar were grouped together. Judgment was used to ensure the correct coding because the determination of the categories is critical (Gay, Mills, \& Airasian, 2011). Identifying too many categories would make analysis difficult but too few categories would mask critical differences. The survey answers were read more than once to confirm the coding results (Fowler, 2014).

The categories identified from the first round survey were emailed back to the initial 18 teachers (Dalkey \& Helmer, 1963) as part of the second round survey (Appendix D). After a week, only five teachers had returned the second survey. Connor, Snell, Gansneder, and Dexter (2010) cautioned that the response rate could be low if the survey was included as an email attachment. Due to the low return rate, the survey was printed on paper and placed in each teacher's mailbox. Four more teachers returned the second survey bringing the sample total to nine teachers, a $33.3 \%$ response rate. Although the goal was ten participants, it was determined that nine teachers was a satisfactory number of participants for this Delphi survey.

The categories developed from the first round survey data were listed in alphabetical order to reduce any perceived priority by the teachers (Hsu \& Sandford, 2007). The teachers ranked the categories and provided justification of their rankings based upon their personal experiences. Individuals are usually able to rank seven plus or minus two items. Delbecq, Van de 
Ven, and Gustafson (1986) recommended if there are approximately 12 categories have the teachers rank the top 5 . If there are 20 categories have the teachers rank the top 8 .

There were 8 categories of limitations and 13 categories of resources. Therefore, the teachers were asked to select and rank their top 5 from both categories. The limitations and resources were assigned points based upon the ranking from the nine teachers who responded. Categories ranked higher received more points while categories which were not ranked at all did not receive any points. The overall point totals (Appendix E) highlight the categories most critical to the teachers.

The data for the teachers' needs also came from a review of teacher certification competencies. Florida teachers are expected to become certified in their field (Fla. Admin. Code R. 6A-4.001, 2001). The certification program requires the teachers to meet certain competencies to earn the desired certification (Fla. Stat. § 1012.56). The round one survey asked the teachers to list the certifications they plan to pursue in the next two to three years. The competencies for these certifications, which were mostly related specifically to AT or ESE, were gleaned from the FLDOE websites.

Certification competencies were compared to the needs identified in the round one survey. Competencies which could be incorporated into an existing category were removed from the list of competencies and the point value for the category was increased. The data from the second round survey was sent back to the teachers in the third round survey (Appendix F).

The final round of the Delphi method was designed to establish a consensus amongst the teachers. This survey provided closure for the study and suggested areas of diversity between the teachers. Finally, the results of this survey established guidelines for future research and 
planning. Based upon the data collected, it was decided that the third round would be the final round.

The results from the third round survey were used as input to the task analysis but could also be used in future research to provide more detail to improve teacher education (Delbeqc, et al., 1986). Prior to sending out the third round survey it was emailed to the three Florida teachers for pretesting (Delbeqc et al., 1986). Following pretesting, the third round surveys were sent via email and placed in the mailboxes as was the process for the second round survey.

The third round survey provided "controlled interaction between the respondents" (Delmer \& Helmer, 1963, p. 459) where the teachers were able to view which categories received the highest point total overall and compare this to their rankings from the second round. The teachers were asked to select and rank their top three limitations and barriers. If the teachers changed their ranking from the second survey, they were asked to explain their rationale for their decision. The goal was to build a consensus of the teachers' top training needs (Dalkey \& Helmer, 1963).

The ranking from the third round survey (Appendix G) were provided to the SMEs for their validation. The categories were broken into quartiles (Appendix G) based upon their point value (Delbecq, et al., 1986). Categories in the top quarter were examined to determine if a consensus was achieved. The second research question, What are the most critical training needs of Florida ESE teachers?, was answered by the results of the third round survey and SME validation comments.

Task Analysis

Morrison, Ross, Kalman, and Kemp (2011) state: "an analysis of the content required for instruction does not begin in a vacuum. It begins with the needs or goals derived from the 
definition of the instructional problem" (p. 78) and "an understanding of the learner's knowledge and background related to the topic" (p. 79). The teachers' needs were derived from the threeround Delphi method. The teachers' background and knowledge are based upon the Delphi survey and the demographic survey.

A task analysis "includes the identification and breakdown of tasks that must be learned and the description of the overt behaviors needed to perform those tasks" (Richey, Klein, \& Tracey, 2011, p. 55). Morrison et al. (2011) described three techniques for performing a task analysis: the topic analysis, the procedural analysis, and the critical incident method. The topic analysis is used to define cognitive knowledge. The procedural analysis is used when dealing with specific tasks or sequence of steps. The critical incident is used for interpersonal skills and attitudes.

The task analysis defined the facts, concepts, principles and rules, procedures, interpersonal skills, and attitudes related to the classification of the data based upon the needs of the teachers. It also required subject matter experts (SMEs) to help define the data related to the issue (Morrison, et al., 2011). The SMEs from the Florida center school and FDLRS were briefed on the needs assessment. The SMEs were asked to review the results and provide their feedback on the documented needs of the teachers.

Based upon the needs assessment and the feedback from the SMEs, the essential knowledge, tasks, and attitudes which must be mastered by the teachers were documented (Appendix H). This is the first step in deriving the content of the proposed professional development instruction (Morrison, et al., 2011). The next step was to cluster the results of the task analysis with the data from the teachers' needs (Appendix H) and write objectives for each of the groups. The last step was to identify the objectives for any essential information not 
incorporated into a group. The instructional objectives were documented in tabular format (Table 8).

Gap Analysis

The required instructional content based upon the task analysis was compared to existing professional development course objectives to determine which of the proposed objectives were met and which were not. The objectives for the district's professional development program were pulled from the district's MIP. The learning objectives for these courses were added to the instructional objectives from the previous step to create a matrix (Appendix I).

Each item from the list of instructional content was compared to the course objectives to evaluate if existing curriculum met the needs of the teachers. If the objective was addressed in current curriculum an ' $\mathrm{X}$ ' was placed in the cell where they intersected. Research question three, How well do existing professional development courses help teachers overcome barriers to implementing AT in the classroom or pursuing certification?, was answered by this matrix.

This matrix may also draw attention to training gaps (i.e., blank cells) which must be addressed to meet the needs of the teachers. Recommendations consisted of whether existing courses could be modified or if new courses needed to be developed to address the training gaps. Research question four, How can a district's professional development curriculum be improved to meet the current needs of its teachers?, was answered by these recommendations.

The final report identified the proposed course objectives not currently addressed by the existing professional development courses. The SMEs were asked to review the final report to validate the recommendations. The final recommendations were provided to the district for incorporation into future curriculum development and teacher training. 


\section{Resources}

The initial data collection process focused on the teachers' needs. Using the Delphi method, three separate surveys were administered to the teachers to reach consensus on their needs. To ensure the validity of the data, a majority of the teachers must complete each of the surveys. Nine teachers completed the second survey, which included all seven teachers who completed the first survey. The third survey was only sent to these nine teachers. Eight teachers returned the third survey. To include the ninth teacher, the data from her second round survey was used to determine whether a consensus was found. This was a valid approach as some teachers who returned the third survey did not change their rankings from the second round survey.

The validation of the first round and third round survey instruments were performed through pretesting conducted with three Florida teachers. These teachers assessed the understandability of the survey questions. They also provided feedback on questions which were confusing or whether they had problems answering certain questions. Additionally, approval was requested and received from both Institutional Review Board at Nova Southeastern University (Appendix $\mathrm{J}$ ) and the district prior to contacting the subjects.

The district's MIP was reviewed to collect the objectives from the professional development curriculum. FLDOE websites were used to gather the certification requirements.

\section{Summary}

Florida in-service teachers lack consistent knowledge of AT and how it can be incorporated in the classroom to educate students with special needs; however, they are required to be the experts on the AT used in their classroom. To document their knowledge in this area they are required to seek certification. 
In order to address this dichotomy, the teachers depend upon professional development courses to prepare them to research, recommend, incorporate, train, and assess the effectiveness of the AT tools in the classroom. A district professional development program was evaluated. A comprehensive prescription for improving this program so that it meets the AT knowledge and skills of teachers was developed for this evaluation.

This goal was achieved using a case study approach. A needs assessment was conducted using a series of surveys with ESE teachers, instructional objectives were developed using task analysis on the needs assessment, and the objectives were compared to the district's existing program. Gaps were identified and recommendations for improvement were provided to the district. The results of this case study, which are presented in chapter 4 , identified areas of improvements to the professional development program so that it meets the required assistive technology knowledge and skills of teachers. 


\section{Chapter 4}

\section{Results}

The planning phase of the needs assessment was discussed in the previous chapter. The remaining three phases, data collection, data analysis, and reporting, are discussed in this chapter. The data collection was part of a comprehensive prescription for reviewing a professional development program to support ESE teachers. Through this review, the data were analyzed and used to recommend changes to a professional development program that meets the AT knowledge and skills of these teachers.

The comprehensive prescription was made up of four distinct sections. A teachers' needs assessment was created using the Delphi method. A task analysis used the needs assessment to develop instructional objectives for the professional development program. These instructional objectives were compared against the existing professional development learning objectives to highlight gaps discovered between these two sets of objectives. These gaps led to specific recommendations which were briefed to school and assistive technology experts for validation. The findings were reported to both the district and the technical specialist at FDLRS. Both groups received a briefing on the methodology and outcomes. This report and feedback from the SMEs are discussed at the end of this chapter. 


\section{Needs Assessment}

The needs assessment was developed by surveying 18 district ESE teachers using the Delphi method, which consisted of multiple rounds of surveys in an effort to create a consensus on the most important problems or limitations the ESE teachers have encountered using AT. The surveys also identified resources which the teachers used to overcome these limitations. These surveys allowed the teachers to rank which limitations and resources were most critical to them. The final survey achieved a consensus of the most important issues amongst all participants.

Additional data, which potentially had some bearing on the training needs of the teachers, were gathered from the first survey. The teachers listed state teacher certifications they desired but had not yet earned as well as any barriers to earning these certifications. The teachers identified types of AT they had problems using along with the impairments and disabilities they encountered in the classroom.

\section{Sample Selection}

The center school chosen had 27 ESE teachers and all teachers were given a consent form and a demographic survey (Appendix A). Eighteen teachers, referred to as volunteers, returned the consent form and survey. Nine teachers, referred to as participants, completed all surveys, a $33.3 \%$ return rate.

The demographic data collected were used to determine if the participants were representative of ESE teachers throughout the state of Florida. Table 1 shows the gender ratio of ESE teachers from the state level down to the nine participants. This figure shows the gender ratio of the volunteers and participants are similar to the gender ratio of ESE teachers from the district and the state (http://www.fldoe.org/accountability/data-sys/edu-info-accountabilityservices/pk-12-public-school-data-pubs-reports/staff.stml) 
Table 1

ESE Teacher Gender Ratio

\begin{tabular}{|c|c|c|c|c|c|}
\hline \multirow[b]{2}{*}{ Teacher Group } & \multicolumn{2}{|c|}{ Female } & \multicolumn{2}{|c|}{ Male } & \multirow[b]{2}{*}{ Ratio } \\
\hline & $\#$ & $\%$ & $\#$ & $\%$ & \\
\hline Florida & 22,103 & $85.78 \%$ & 3,665 & $14.22 \%$ & $6: 1$ \\
\hline District & 290 & $80.56 \%$ & 70 & $19.44 \%$ & $4.1: 1$ \\
\hline Volunteers & 14 & $77.78 \%$ & 4 & $22.22 \%$ & $3.5: 1$ \\
\hline Participants & 8 & $88.89 \%$ & 1 & $11.11 \%$ & $8: 1$ \\
\hline
\end{tabular}

The participants also represent teachers with various experience levels. The range of years teaching goes from first year teachers to 19 year veterans for both volunteers and participants. The median experience level for the volunteers was 6.75 years and the mean was 7.2 years. The median experience level for the participants was 8 years and the mean was 8.5. These data show that less experienced teachers decided not to participate. Five out of the nine who chose not to participate had fewer than four years of teaching experience.

The final demographic data analyzed were the grade level taught. The goal was to survey a sample from all grade levels. Figure 1 shows that both the volunteers and the participants provided complete coverage from PK to 12th grade. Overall, these data show that the participants for the needs assessment were representative of Florida ESE teachers. 


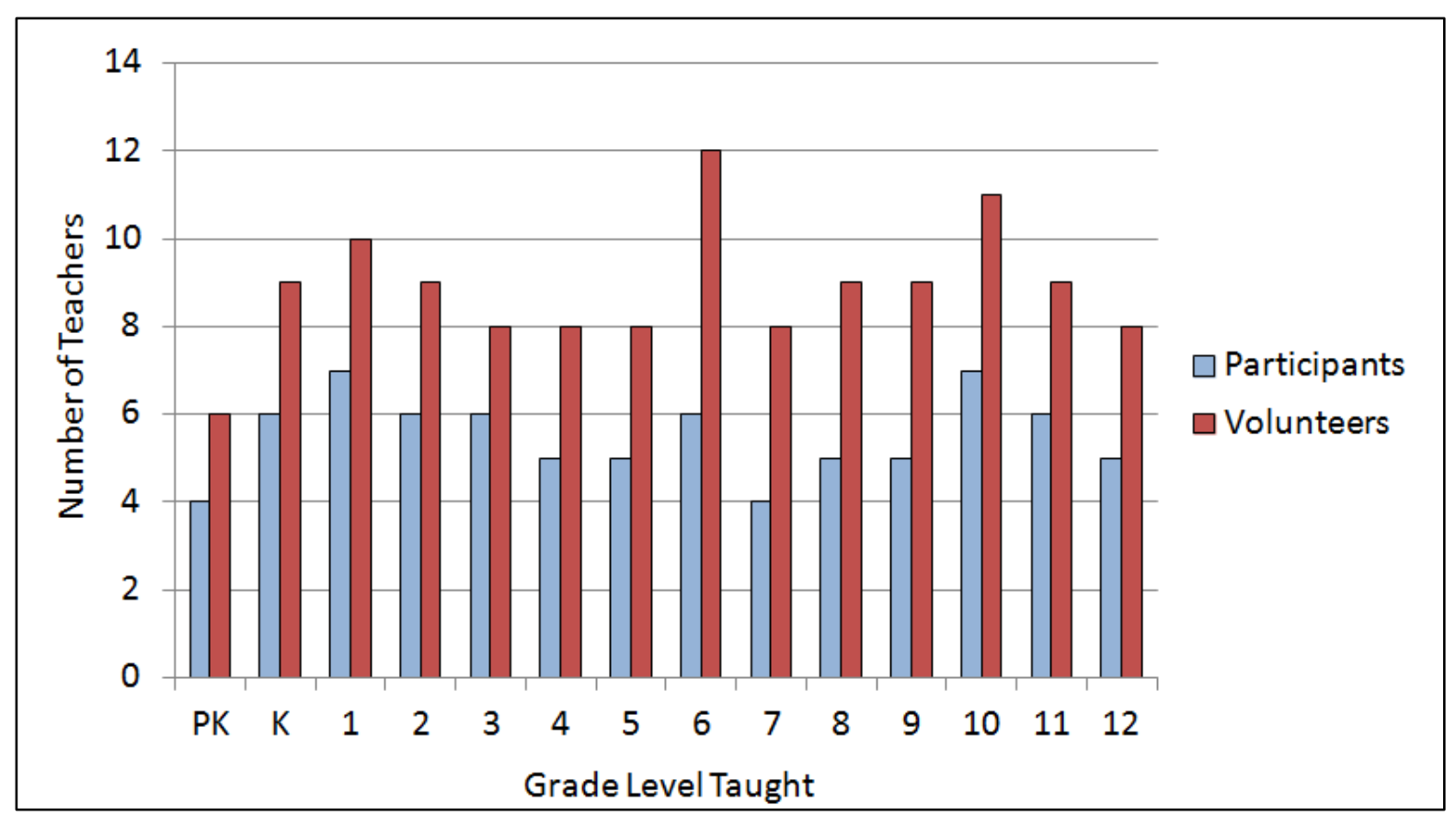

Figure 1. Grade Level Coverage of Participants and Volunteers

\section{Initial Data}

The first survey (Appendix B) asked open-ended questions to gather data on three main issues: limitations the teachers had encountered using AT in the classroom, which resources were effective in overcoming the limitations, and what certifications were the teachers planning to earn in the future. The answers from the teachers related to the limitations and resources were coded to identify the main points in the teachers' answers. Florida teacher certifications, pulled from FLDOE websites, were examined to determine if they clarified the training needs of the teachers.

In order to answer the first research question, data from the first survey related to limitations encountered by the teachers were coded. Appendix $C$ shows the data with the codes highlighted. Eight limitations were identified which adversely impacted the effective use of AT in the classroom (Table 2). 
Table 2

Identified Limitations Affecting AT Implementation

\section{Limitations}

Lack of experience using needed AT

Lack of knowledge of AT available in the market place

Lack of knowledge of AT available in school

Lack of resources to learn about AT

Lack of training on needed AT

Malfunctions with AT

Uncertainty on which AT to use to support various students' needs

Unfamiliarity with how AT works to support students' needs

The teachers also identified 13 methods or resources they utilized to overcome the limitations they encountered. These are listed in Table 3.

Table 3

Identified Resources Which Overcame Limitations

Resources

Attending training courses

Collaborated with other teachers

Experimented with AT

Hands-on use of AT

Observed other teachers using AT

Participating in weekly Professional Learning Communities (PLCs)

Persistence

Practicing with AT

Reviewed online training

Trial and error

Worked with Occupational Therapist

Worked with Speech Language Pathologist

Worked with Technology Specialist/Technology Resource Teacher/TechCon 
On the demographics survey, the teachers were asked to list the certifications they had already earned. On the first round survey they were asked which certifications they wanted to earn. The teachers were also asked what barriers were holding them back from earning the certifications. The main reasons were time and money. Reviewing the certification requirements did not add any information to the data collected on limitations from the first survey and modifying the professional development program would not overcome the time or money limitations. Therefore, no data related to certifications were included in the second round survey. Ranking of Limitations

The limitations and resources from the first survey were included in the second and third round surveys to call attention to the most critical needs of the teachers. The second round survey (Appendix D) provided all 18 teachers with an alphabetized list of the limitations and resources. The teachers were asked to select five items in each category which, in their opinion, had the most impact to the effective use of assistive technology. They were then asked to rank these five limitations and resources from most important (1) to least important (5). Nine teachers completed the second round survey.

Once the second round surveys were received, the limitations and resources were given value points based upon the ranking from the teachers. Limitations and resources ranked as number one were given five points. Limitations and resources ranked as number two were given four points and so on for the rest of the top five. Limitations and resources which were not ranked in the top five were not given any points. Appendix E contains the rankings and value points for the limitations and resources from the second survey.

The initial ranking and the teachers' rationale for their ranking in the second round were included in the third round survey (Appendix F). This allowed the teachers to compare their 
rankings with the overall ranking from all teachers. The teachers were given the opportunity to modify their ranking from the second round survey but could only select their top three in each category instead of the top five. Through this process some of the teachers modified their rankings. One teacher raised her ranking of malfunctions from the second to third survey because she had noted problems with "required [software] updates, WiFi issues, and some other malfunctions" following the second survey.

The updated rankings were evaluated and the value points given in the same manner as during the second round except points were only given to the top three in each category. All but one of the teachers from the second round completed the third round survey. For this teacher the ranking from the second round was used but the limitations and resources ranked fourth and fifth received no points. Appendix G contains the rankings and value points for the limitations and resources from the third survey.

Table 4 shows the comparison of the limitations rankings from the second and third surveys. The limitations of Malfunctions with AT and Lack of training on needed AT both increased in value from the second to the third round. In contrast, all other limitations decreased in point value. 
Table 4

Limitation Value Points

\begin{tabular}{lcc}
\hline Limitations & $\begin{array}{c}\text { Second Round } \\
\text { Value Points }\end{array}$ & $\begin{array}{c}\text { Third Round Value } \\
\text { Points }\end{array}$ \\
\hline $\begin{array}{l}\text { Malfunctions with AT } \\
\text { Lack of training on needed AT }\end{array}$ & 22 & 30 \\
$\begin{array}{l}\text { Lack of knowledge of AT available in the } \\
\text { market place }\end{array}$ & 19 & 22 \\
$\begin{array}{l}\text { Lack of knowledge of AT available at school } \\
\text { Lack of experience using needed AT }\end{array}$ & 18 & 13 \\
$\begin{array}{l}\text { Uncertainty of which AT to use to support } \\
\text { various students' needs }\end{array}$ & 19 & 11 \\
$\begin{array}{l}\text { Lack of resources to learn about AT } \\
\text { Unfamiliarity with how AT works to support } \\
\text { students' needs }\end{array}$ & 14 & 3 \\
\hline
\end{tabular}

During a meeting with district personnel on the results of the needs assessment, the center school principal agreed with the majority of the limitations reported by the teachers; however, she commented that the lack of knowledge of AT available to the teacher was not a valid need. The school's policy was not to inform teachers of new technology because funds are not available to purchase all desired AT devices. The top priority for funding is the AT required by students' IEPs. After these purchases, there are little or no discretionary funds remaining for additional AT devices. Therefore, the two limitations related to lack of knowledge were removed from the list of critical needs.

The round two and round three surveys were analyzed once again after removing Lack of knowledge of AT in the market place and Lack of knowledge of AT in the school. Limitations ranked lower than these items, if any, were moved up in ranking.

The comparison of value points from the second round to the third round with these changes is shown in Table 5. Following the removal of the two knowledge limitations, Lack of 
training on needed AT was ranked higher than Malfunctions with AT after the second survey.

Malfunctions with AT was the only limitation which increased in value in third survey and Lack of training on needed AT fell to second. However, even with the decline in the value points, Lack of training on needed AT totaled nearly as many value points as all remaining limitations combined.

Table 5

Limitation Value Points with Knowledge Categories Removed

\begin{tabular}{lcc}
\hline Limitations & $\begin{array}{c}\text { Second Round } \\
\text { Value Points }\end{array}$ & $\begin{array}{c}\text { Third Round Value } \\
\text { Points }\end{array}$ \\
\hline Malfunctions with AT & 25 & 31 \\
Lack of Training on Needed AT & 26 & 24 \\
Uncertainty of which AT to use to support & 17 & 12 \\
various students' needs & 22 & 11 \\
$\begin{array}{l}\text { Lack of experience using needed AT } \\
\text { Lack of resources to learn about AT }\end{array}$ & 18 & 4 \\
$\begin{array}{l}\text { Unfamiliarity with how AT works to support } \\
\text { students' needs }\end{array}$ & 9 & 0 \\
\hline
\end{tabular}

\section{Ranking of Resources}

The same methodology was utilized to analyze the resources as was used for limitations. The comparison of the resource rankings for the second and third rounds is shown in Table $\mathbf{6}$. This table shows that the only resources which increased in value from the second to the third round were Worked with Speech Language Pathologist and Worked with the Technology Specialist. 
Table 6

Resource Value Points

\begin{tabular}{lcc}
\hline Resources & $\begin{array}{c}\text { Second Round } \\
\text { Value Points }\end{array}$ & $\begin{array}{c}\text { Third Round } \\
\text { Value Points }\end{array}$ \\
\hline $\begin{array}{l}\text { Worked with Speech Language } \\
\text { Pathologist }\end{array}$ & 27 & 31 \\
$\begin{array}{l}\text { Worked with Technology Specialist/ } \\
\text { Technology Resource Teacher }\end{array}$ & 13 & 16 \\
Practicing with AT & 19 & 12 \\
Trial and Error & 18 & 9 \\
Hands-on-Use of AT & 12 & 8 \\
Participated in weekly Professional & 9 & 7 \\
Learning Communities (PLCs) & 12 & 6 \\
Experimented with AT & 9 & 3 \\
Collaborated with Other Teachers & 7 & 3 \\
Worked with Occupational Therapist & 4 & 0 \\
Persistence & 4 & 0 \\
Reviewed Online Training & 2 & 0 \\
Attended Training Courses & 1 & \\
Observed Other Teachers Using AT & & 3 \\
\hline
\end{tabular}

After additional reflection, the resources Trial and error, Hands-on use of AT, Practicing with AT, and Experimented with AT were determined to be duplicative. Each of the resources required hands-on access to the AT. Therefore, these resources were combined into a single resource called Hands-on use of AT. Table 7 shows how the rankings changed with this combined resource. 
Table 7

Resource Value Points with Hands-on use of AT Categories Combined

\begin{tabular}{lcc}
\hline Resources & $\begin{array}{c}\text { Second Round } \\
\text { Value Points }\end{array}$ & $\begin{array}{c}\text { Third Round Value } \\
\text { Points }\end{array}$ \\
\hline Hands-on-Use of AT & 38 & 34 \\
Worked with Speech Language Pathologist & 30 & 31 \\
Worked with Technology Specialist/ & 13 & 16 \\
Technology Resource Teacher & 11 & 8 \\
Participated in weekly Professional Learning & 10 & 6 \\
Communities (PLCs) & 8 & 4 \\
Collaborated with Other Teachers & 4 & 3 \\
Worked with Occupational Therapist & 4 & 0 \\
Persistence & 2 & 0 \\
Reviewed Online Training & 2 & 0 \\
Attended Training Courses & & \\
Observed Other Teachers Using AT & & \\
\hline
\end{tabular}

Combining the Hands-on categories show the teachers believe that having access to AT for hands-on testing and evaluation is a critical resource. Although the value points for Hands-on use of $A T$ decreased from the second to third round, it still was ranked highest of all resources. The teachers also highlighted the importance of working with the school staff. Working with the Speech Language Pathologist and Technology Specialist were the only resources to increase in value from the second to the third round. During the district meeting, the center school principal mentioned her concern that this may show the teachers depend on the school staff too much. More effort must be taken to ensure the teachers can use AT with minimal support from the staff.

Looking at the resources which were not ranked highly brought up an interesting point. The teachers did not consider training to be a viable option for overcoming limitations. The center school principal commented that there are limited AT courses available to the teachers. She believed this could be the cause of this lower ranking. 


\section{Consensus}

After the third survey was completed, the limitations were analyzed to assess if a consensus had been achieved. This determination was made by dividing the limitations based upon their quartile rank. The process for this analysis is discussed in Appendix G.

The limitations in the top quarter for both the second and third rounds were Malfunctions with AT and Lack of training on needed AT. Although Lack of training on needed AT went down in value from the second to the third round after the knowledge limitations were removed, it still received significantly more points than all the other limitations. Therefore, Malfunction with AT and Lack of training on needed AT were named as the consensus limitations. These two limitations answer the second research question and were used during the task analysis to identify the critical learning objectives required by Florida ESE teachers.

\section{Task Analysis}

The task analysis takes into account the needs assessment and an analysis of the characteristics of the teachers. Using the consensus limitations from the needs assessment and the demographic survey results reported previously, the tasks required by the teachers were identified and broken down. Additionally, the overt behaviors required for these tasks were identified. This task analysis was broken down into two distinct phases: Topic Analysis and Procedural Analysis.

Topic Analysis

The topic analysis looks at the tasks and the learners. The data from the needs assessment showed the consensus limitations to be Malfunctions with AT and Lack of training on needed AT. The teachers needed to respond quickly if the AT failed to operate properly. They must 
determine if they can resolve the AT problems or if they need to switch to alternative AT. This is critical to ensure the focus remains on the student and not the AT.

The teachers also requested additional training on the AT in the classroom which is required for their students, especially AT which they do not currently use in the classroom. However, this training must be applicable to a broad range of teachers. The teachers who participated ranged from first-year teachers to 19-year veterans. Additionally, the teachers have taught all grade levels from PK to 12th grade.

The data for this topic analysis were based upon the coding of the teachers' comments from the second and third round surveys. The table in Appendix H categorizes the knowledge required by the teacher into the six areas of the topic analysis. The analysis of these data uncovered the required content of instruction.

During the district meeting, the center school principal tied the reason for perceived malfunctions to problems with the network in the school instead of the actual devices malfunctioning. The school's location causes network outages, which cannot be changed through the training of teachers. Based upon these data, teachers must be able to quickly identify if the AT is not working due to network problems or actual malfunctions.

Once the teachers have determined the cause, they must quickly find a solution. While the teacher is troubleshooting the AT she is not able to focus on the student. This could cause a problem based upon the student's temperament. The student may wait patiently or could react angrily. Therefore, the teacher has to decide, in a timely manner, if the best course of action is to forego the use of the high tech AT and utilize alternate methods, to include low-tech AT. This decision process must be an objective of the AT training. 
Teachers must also have confidence in their ability to use AT. Otherwise they will become less effective. The various areas for this training include identification of AT for a specific disability or impairment, incorporating AT into the curriculum, and identifying if AT would be effective to other students in the classroom.

\section{Procedural Analysis}

The procedural analysis details specific procedures and steps necessary to perform a function. The main procedural aspect of AT is a step-by-step process for troubleshooting network and non-network related problems with AT. The process must be straightforward and allow the teacher to quickly make decisions on how to continue classroom instruction with limited interruption if the AT is not working. This requires a basic knowledge of the various systems and an easy to follow process to correct problems with AT. As stated previously, if a simple solution is not available, an alternative instructional method must be readily available.

\section{Required Instructional Objectives}

As Richey, Klein, and Tracey (2011) point out "the output of the task analysis serves as an input for developing behavioral objectives" (p. 55). The development of instructional objectives is made up of four steps: review of the task analysis and identification of essential knowledge, tasks, and attitudes required of the learner; grouping the task analysis into clusters with the needs identified; writing an objective for each of the clusters; and writing objectives for additional information that is essential but not covered by an objective (Morrison, et al., 2011).

The essential knowledge, tasks, and attitudes were developed based upon the needs assessment and the task analysis. The comments from the needs assessment were coded and grouped into five clusters. The comments and clusters are listed in Appendix H. 
These clusters were examined and training objectives were written for each set of needs listed. Training objectives are made up of a description of the observable behavior, conditions under which the students exhibit the behavior, and the criterion which describes how well the student must perform the task (Richey, et al., 2011). Five training objectives were created from this analysis. These objectives are listed in Table $\mathbf{8}$.

Table 8

Training Objectives Derived from Task Analysis

\begin{tabular}{lll}
\hline Observable behavior & Conditions for behavior & Criterion for success \\
\hline $\begin{array}{l}\text { Analyze AT options to } \\
\text { support students }\end{array}$ & $\begin{array}{l}\text { When an exceptional student } \\
\text { is in classroom }\end{array}$ & $\begin{array}{l}\text { Selection of valid AT based } \\
\text { upon assessment of student's } \\
\text { needs }\end{array}$ \\
$\begin{array}{l}\text { Employ AT based upon } \\
\text { specific needs of students }\end{array}$ & $\begin{array}{l}\text { Classroom where } \\
\text { exceptional students are } \\
\text { present }\end{array}$ & $\begin{array}{l}\text { Effectively keeping student } \\
\text { actively engaged in lesson }\end{array}$ \\
$\begin{array}{l}\text { Stay current on new assistive } \\
\text { technologies }\end{array}$ & $\begin{array}{l}\text { Ongoing. Technology } \\
\text { changes constantly }\end{array}$ & $\begin{array}{l}\text { Perform online searches and } \\
\text { research to identify new } \\
\text { technology }\end{array}$ \\
$\begin{array}{l}\text { Categorize errors with AT } \\
\text { and apply appropriate } \\
\text { corrective actions }\end{array}$ & $\begin{array}{l}\text { AT is not working in the } \\
\text { classroom }\end{array}$ & $\begin{array}{l}\text { Identify the cause of error } \\
\text { and possible resolutions }\end{array}$ \\
$\begin{array}{l}\text { Choose alternatives if AT is } \\
\text { not working }\end{array}$ & AT cannot be fixed quickly & $\begin{array}{l}\text { Identify AT devices, low- } \\
\text { tech and mid-tech, which } \\
\text { can be utilized if high-tech } \\
\text { AT on available }\end{array}$ \\
\hline
\end{tabular}

\section{Gap Analysis}

Identifying gaps in the professional development program highlight possible changes which can be made to improve the knowledge and skill of district ESE teachers. The gaps also identify areas of the program requiring immediate attention. 


\section{Coding of Professional Development Objectives}

The district's Master In-service Plan (MIP) was reviewed by searching for terms related to the five instructional objectives created during the task analysis. This review consisted of multiple passes until no new terms were discovered. Table 9 shows the search terms found along with the applicable instructional objective.

Table 9

Master In-service Plan Search Terms Related to Derived Instructional Objectives

Instructional Objectives

\begin{tabular}{|c|c|c|c|c|c|}
\hline Search Terms & $\begin{array}{l}\text { Analyze } \\
\text { options } \\
\text { available } \\
\text { in AT }\end{array}$ & $\begin{array}{c}\text { Employ } \\
\text { AT } \\
\text { based } \\
\text { upon } \\
\text { specific } \\
\text { needs } \\
\text { of } \\
\text { students }\end{array}$ & $\begin{array}{l}\text { Stay current } \\
\text { on new } \\
\text { assistive } \\
\text { technologies }\end{array}$ & $\begin{array}{c}\text { Categorize } \\
\text { errors with } \\
\text { AT and } \\
\text { apply } \\
\text { appropriate } \\
\text { corrections }\end{array}$ & $\begin{array}{c}\text { Choose } \\
\text { alternatives } \\
\text { if } \mathrm{AT} \text { is } \\
\text { not } \\
\text { working }\end{array}$ \\
\hline Adaptive devices & $\mathrm{X}$ & $\mathrm{X}$ & & & \\
\hline Adaptive equipment & $\mathrm{X}$ & $\mathrm{X}$ & & & \\
\hline Applicable technology & $\mathrm{X}$ & & & & \\
\hline $\begin{array}{l}\text { Appropriate assistive } \\
\text { technology }\end{array}$ & $X$ & & & & \\
\hline Appropriate software & & $\mathrm{X}$ & & & \\
\hline Current trends & & & $\mathrm{X}$ & & \\
\hline $\begin{array}{l}\text { Determining appropriate } \\
\text { modifications }\end{array}$ & $X$ & & & & \\
\hline Develop variations & & & & & $X$ \\
\hline Evaluation process & $X$ & & & & \\
\hline Identify computer & & $X$ & & & \\
\hline $\begin{array}{l}\text { Incorporating assistive } \\
\text { technology }\end{array}$ & $\mathrm{X}$ & & & & \\
\hline Individual student's needs & & $\mathrm{X}$ & & & \\
\hline Integrate the use of computers & & $\mathrm{X}$ & & & \\
\hline $\begin{array}{l}\text { Knowledge of } \\
\text { accommodations }\end{array}$ & & $\mathrm{X}$ & & & \\
\hline $\begin{array}{l}\text { Knowledge of assistive } \\
\text { technology }\end{array}$ & & $\mathrm{X}$ & & & \\
\hline Knowledge of resources & $X$ & & & & \\
\hline Professional resources & & & $\mathrm{X}$ & & \\
\hline Relevant research & & & $\mathrm{X}$ & & \\
\hline
\end{tabular}


Teaching with manipulatives

Technical assistance

Technology available

Technology for classroom
$\mathrm{X}$

$\begin{array}{lll}X & X \\ X & X & \\ \end{array}$

\section{List of Professional Development Courses}

The search terms were used in the district's MIP to identify where the current training addressed proposed training objectives. The MIP listed 256 courses which are offered to the district's teachers. This analysis discovered 36 courses which contained the search terms listed in Table 9.

\section{Gap Matrix}

The 36 professional development courses identified were combined with the five proposed instructional objectives to form a matrix (Appendix I). If the course was determined to meet the instructional objectives an ' $\mathrm{X}$ ' was placed in the cell where the course and the instructional objectives intersected. Cells under an instructional objective without an ' $\mathrm{X}$ ' signified the course did not meet the requirements of that objective. This matrix answers the third and fourth research questions.

The gap matrix shows that two objectives are satisfactorily covered by existing courses. The objective of employing AT based the specific needs of students is covered by 25 out of the 36 courses. Demonstrating the ability to understand change in technology is covered by 11 out of the 36 courses. These objectives may not require additional instructional support for the teachers.

The remaining three objectives, however, would need to be addressed to increase the coverage within the professional development program. Analyzing options available in AT was addressed in only 6 of the 36 courses. The last two objectives, categorize and correct AT errors and choose AT alternatives, were only covered by one course each. 
Although not specifically stated in the objectives, UDL was also used as a search term in the MIP and only one course identified this term, ESE Issues - Administrators. This course is designed for administrators; therefore, teachers do not have any courses which train them on UDL. In each of these cases more focus should be added to the professional development courses to better prepare ESE teachers to understand UDL.

There are some issues which professional development courses cannot fully address. For these issues the school can provide needed support. An example of a needed tool for ESE teachers would be for the school technology specialist to develop a basic troubleshooting guide for network and AT problems. This guide would be placed in each classroom containing AT devices for quick response to errors or malfunctions.

\section{Reporting}

The results were briefed to two sets of SMEs. The first group was from the district. The individuals present were all from the center school. The principal, assistant principal, curriculum resource teacher, and an ESE teacher were present for the briefing of the results. The second briefing was given to the FDLRS technology specialist.

The SMEs were briefed on the needs assessment. The process was explained and the results of the surveys were detailed. At the conclusion the attendees were asked to provide feedback on the results of the needs assessment. Based upon their comments, some of the needs found were removed from consideration, as explained previously.

The results of the task analysis and gap analysis were then briefed to both groups. The attendees were again asked to provide feedback. Both groups responded positively to the results and were appreciative for the recommendations. The center school principal confirmed that she would ensure the results were provided to the district, especially the comments on the current 
professional development program. She acknowledged the need for a troubleshooting guide for the teachers. She also planned to incorporate more demonstration and hands-on learning during the PLCs.

The FDLRS technology specialist confirmed that new programs rolling out this semester were directed to resolve many of the issues reported. According to her, the biggest difficulty is getting teachers out of the classroom. The AT in the Classroom course is designed to go to the districts and individual schools to make it easier for teachers to attend. The goal is to provide teachers with the ability to see and interact with various AT devices.

\section{Summary of Results}

Malfunctions with AT and Lack of training on needed AT are the most critical needs of the teachers. Teachers feel they do not get the training they need but they do not see training as a resource which can help them. The teachers prefer working with the school staff, particularly the Speech Language Pathologist, and gain confidence with AT through hands-on testing and evaluation.

Five instructional objectives were developed which would meet the training needs of ESE teachers using AT in the classroom. These objectives were compared against existing professional development courses to determine whether existing courses satisfy the teachers' needs or if changes are required.

Two objectives were found to be sufficiently covered and three objectives require additional coverage within future professional development courses. Additionally, support from the school would provide needed assistance to ESE teachers. Recommendations from the gap analysis are addressed in the next chapter. 


\section{Chapter 5}

\section{Conclusions, Implications, Recommendations, and Summary}

As a culmination of the comprehensive prescription described in chapter four, the data from each of the phases have been analyzed. The findings from the analyses have been briefed to district and state subject matters experts (SMEs). Based upon the feedback from the SMEs, conclusions and implications were identified and are reported in this chapter. The conclusions and implications led to specific recommendations for the districts and individual schools which are also reported. A summary concludes this chapter.

\section{Conclusions}

Each phase of the comprehensive prescription provided insight to answer the research questions.

Research Question One

The first research question, What barriers have been reported to the effective use of assistive technology in the classroom?, was answered by the analysis of the first survey. The teachers provided a glimpse into the problems they are currently encountering using AT in the classroom.

The teachers pointed out a lack of confidence in using AT in the classroom to support students with special needs. They did not have knowledge of what AT was available in the marketplace or what AT the school possessed which they could use. The teachers desired more 
experience on the various AT systems so they could more effectively use them or to troubleshoot malfunctions when they occurred. Finally, the teachers did not feel they were sufficiently trained nor had access to resources to help them use AT.

\section{Research Question Two}

The second research question, What are the most critical training needs of Florida ESE teachers?, was answered with the analysis of the third survey. Providing the teachers the opportunity to share their concerns and see how other teachers responded offered a structured method of obtaining a consensus of limitations.

The teachers agreed that lack of training and malfunctions with AT posed the greatest barriers to implementing AT in the classroom. Although the major problem may not have been actual malfunctions but network outages, the teachers need skills to identify problems and correct them quickly or transition to other tools. Finally, they felt they would benefit from more hands-on experience with AT.

\section{Research Question Three}

The third research question, How well do existing professional development courses help teachers overcome barriers to implementing AT in the classroom or pursuing certification?, was answered with the creation of the gap matrix. This matrix shows how well the various professional development courses address the needs of the teachers.

The district has 256 professional development courses but only 36 were found to support ESE teachers. Two proposed instructional objectives are reasonably covered by existing professional development courses. Employ AT based upon specific needs of students is well covered by 25 different courses. Demonstrate ability to understand changes in technology is covered by 11 courses. Teachers are able to utilize AT in the classroom once they have mastered 
the areas they need. Understanding new functions or updates to the current AT is critical to allow the teachers to meet the needs of their students. On-going training and professional learning communities in the school are mandatory to help teachers build their knowledge and experience.

\section{Research Question Four}

The last research question, How can a district's professional development curriculum be improved to meet the current needs of its teachers?, is answered by examining the gaps or areas of the gap matrix which do not have an ' $\mathrm{X}$ '. These areas require a review to determine how the existing program can be improved to fill the various gaps.

Three instructional objectives do not have coverage by existing professional development courses. Analyze options available in AT is only covered by six different courses. Both Categorize errors with AT and apply appropriate corrections and Choose alternatives if AT is not working have coverage by only one course.

\section{Implications}

Development of additional professional development courses will provide teachers with required knowledge and experience. In turn, this will reduce the teachers' dependence on the school staff. However, the school is instrumental in guaranteeing that teachers and school staff share information effectively. Teachers commented that they have limited time for training due to their "demanding schedules at work." The schools should provide local training; this is critical to reduce the teachers' time out of the classroom.

The Speech Language Pathologist (SLP) is a critical resource to teachers using AT with their students. However, they cannot effectively provide constant support to all teachers. Providing teachers with additional opportunities to gain experience with AT on their own will 
free up valuable time for all staff members, not just the SLP, to proactively implement programs which will improve the education for all exceptional students.

O’Malley, et al. (2013) stated that the students were disappointed when they returned to low tech AT. However, in the event the high tech AT is not available, the teacher must utilize the low tech AT. It is better to have some AT than none at all. As Van Laarhover and Conderman (2011) found, teachers should be on the lookout for new AT, both high tech and low tech. The teachers highlighted the fact that they are not always aware of the latest technology and leave this research to the technology specialist or the Speech Language Pathologist. Processes for sharing this information to all teachers should be examined to ensure an undue burden is not placed on the school staff.

The training on AT is not timely. The teachers reported that they do not have the training to use AT. However, as speed of technology changes increases, the courses offered to a teacher two or more years ago are outdated (Peterson-Karlan, 2015). Smith and Tyler (2011) point out that pre-service teachers are overwhelmed by the amount of information they are given. This does not change once they are out of school. Teachers reported that there is too much information available on AT and they cannot comprehend it all and, once again, the responsibility falls to the school staff to understand the current state of AT. The districts and individual schools must provide continual education programs to all ESE teachers helping them maintain and improve their AT skills and knowledge.

Gilakjani, et al (2013) reported the biggest barrier to the use of AT is the lack of training. Teachers confirmed that lack of training was one of the biggest barriers to using AT. The teachers reported that a major resource which helped to overcome this barrier was getting hands- 
on experience on the AT and being able to test it outside of the classroom. This confirmed what Van Laarhoven and Conderman (2011) had found.

\section{Recommendations}

Continual education programs could include development of a quarterly AT newsletter identifying best practices for AT devices currently employed by teachers. Additionally, as malfunctions and networks outages impact the education of exceptional students, troubleshooting guides should also be developed and placed in each classroom. Teachers should be able to fix minor issues with AT used in their classroom. Likewise, they should identify issues which cannot be resolved quickly and transition to alternate AT devices, to include low tech AT. The main goal is to keep the focus on the students to ensure the lesson objectives are accomplished.

Florida districts and schools should utilize the resources provided by FDLRS. First and foremost, all applicable PDA courses should be included in the district's MIP along with complete description of the course objectives. Schools should also take advantage of the Technology Specialist at their respective FDLRS Resource Center. Finally, schools and teachers will benefit from the FDLRS' AT in the Classroom training course. Due to limited budgets, this would be an incredibly important resource to help teachers learn if new technology will benefit their students with IEPs.

Teachers desire more hands-on experience with AT devices to improve their confidence and skills. Funding is a tremendous limitation in acquiring AT for practice. Florida districts can utilize two sources to provide information on AT devices for their teachers at little or no cost: FDLRS AT \& UDL Loan Library and the National Center on Accessible Instructional Material online tool (AIM Navigator). 
The Loan Library makes AT devices available to districts to determine if these devices would be effective for their teachers. Borrowing the devices allow the teachers to evaluate AT without expense. Once devices have been proven to be effective, the schools and districts are more confident in purchasing the required devices to support their students. FDLRS is also implementing an "AT in the classroom" course where teachers are invited to examine and use AT devices. The goal of this course is to increase the teachers' awareness and hands-on experience with AT and give the teachers practical information on various AT devices or services which could benefit their students.

The AIM Navigator is an online tool "designed to help IEP teams make decisions about accessible instructional materials for individual students" (Dell et al., 2012, p. 78). The more knowledge about how a device will work in the classroom provides justification to support the identification of AT devices in support of students' IEPs.

Other school districts' professional development programs should be analyzed using the same comprehensive prescription described above. The data from the various schools can be used to determine if a consensus is found or if other issues are more important. Additional assessments of districts' professional development programs will create a more complete picture of the current training needs for AT in the classroom.

The FLDRS Technical Specialist brought up two key issues related to the needs of the teachers. First, she found the term "malfunctions" to be nebulous. The teachers and school administrators were not consistent in their definition of malfunctions. They used terms such as required software updates, internet issues, data errors, as well as other undefined malfunctions which interrupted the flow of the lesson. More research should be performed on the specific technical issues encountered by the teachers and how their impact can be diminished. 
The second issue was the apparent focus on digital or high-tech AT. The teachers specified six AT devices in the first round survey and only one device was low-tech, picture cards. ESE teachers should be surveyed to discover what they think of when they hear AT. This will help to understand if the teachers have a solid foundational knowledge of low-tech and midtech AT and how low-tech and mid-tech AT can be used together with high-tech AT as three legs of AT support for ESE students.

\section{Summary}

The goal of this research was to provide a comprehensive prescription for providing a professional development program and suggesting changes so it meets the assistive technology knowledge and skills of teachers. The target audience for this research was the ESE teachers who use AT, school administrators, and professional development coordinators.

This comprehensive prescription was made up of three parts: a teacher needs assessment (Delphi method/three rounds of surveys), professional development training objectives (task analysis), and recommendations for updates to the professional development program and teacher training (gap analysis).

A Central Florida center school was chosen as the site for this study. The school has 27 ESE teachers. Initially, 18 of these teachers volunteered to participate in the research and returned a demographics survey. Nine of these teachers participated in the entire study.

The original 18 participants completed a demographic survey. Key demographic data showed the participants were representative of Florida ESE teachers. The range of experience for both volunteers and participants were from 1 to 19 years. The median of the experience of the participants was 8 years and the mean was 8.5 years. This is slightly higher than the statistics from all volunteers due to the fact that over half of these individuals who did not participate had 
three years of less experience. The participants also had experience in all grade levels from PK to $12^{\text {th }}$ grade.

The Delphi method was used for the needs assessment. A three-round survey was conducted to identify a consensus of the most critical limitations ESE teachers encountered to the use of AT in the classroom. The first round survey used open-ended questions to allow the teachers to identify limitations they had encountered personally. The data from the first round survey were coded and analyzed to identify categories. The second and third round surveys asked the teachers to rank their top limitation categories. A consensus of the most critical limitations formed following the third round survey.

In addition to the limitations, the teachers were asked to list the resources they used to help integrate AT and what certifications they had earned and which they still desired. The resources provided insight for what could be used to help teachers. Certifications were examined to determine if there were any issues that could be added to the needs assessment which were not highlighted by the limitations.

Eight limitations and twelve resources were identified from the first round survey. Examination of the certifications did not uncover any additional needs for the teachers; therefore, only the lists of limitations and resources were incorporated into the second round survey. Both lists were in alphabetic order to avoid the perception of priority. The teachers were asked to select the top five from each list and then rank them in order of preference. Nine teachers completed the second round.

The results of the second round survey were sent back to the teachers in the third survey along with their individual rankings. The teachers were asked to select and rank their top three 
from each category. Eight teachers completed the third round survey. Data from the second round survey was used to provide data for the ninth teacher.

In order to analyze the limitations and resources quartiles were calculated to break up limitations and resources in quarters. This allowed the identification of the most critical limitations and resources. The limitations in the top quarter were acknowledged as consensus limitations. Based upon the data, the limitations were Malfunctions with AT and Lack of training with needed AT. These limitations were used as the basis for the task analysis to identify critical instructional objectives for the teachers.

Task analysis was used to discover and break out the tasks required by ESE teachers and to categorize the behaviors needed to perform these tasks. The input to the task analysis was the needs assessment created from the teacher surveys. Additionally, the demographic data provided necessary information on the teachers themselves for the task analysis. Two techniques of the task analysis were conducted: topic analysis and procedural analysis

Within the topic analysis the consensus limitation from the needs assessment were reviewed to glean certain factors to help design instructional objectives for teacher professional development courses. The main issues affecting the use of AT was its ineffectiveness due to equipment or network problems and overall lack of training.

Related to the lack of training, teachers were dependent on school staff to ensure they were using the AT correctly. Much of this relates to the fact that technology is constantly changing. Teachers must maintain knowledge on existing technology and understand that technology changes. New AT may provide an enhanced education to their students.

Teachers must also be aware of the fact that the AT devices may fail to work properly. The causes of these failures range from actual equipment failures to the loss of network 
connectivity. Many AT devices require the Internet to work effectively. In the event the AT device does not perform as excepted, the teacher must quickly and effectively return the AT to working order or seamlessly change to another AT device or service to ensure the student is kept engaged. Teachers reported exceptional students could become agitated if their schedule is significantly altered. The teacher must have the wisdom and flexibility to use the best method available to keep the student engaged in the lesson. The main finding related to technology is the teachers must have the ability to correct issues with existing AT to free up the school staff so they can be more proactive in supporting teachers and students.

The procedural analysis was conducted to highlight functions which are procedural in nature. Procedural processes should be repeatable. The main procedures for the ESE teachers are the steps required to determine the cause of AT problems. Teachers require simple checklists to identify common issues encountered with AT devices along with simple corrective actions which can be performed in the classroom to make the devices work again. The checklist can also identify problems which require the help of the school staff.

The results of the task analysis pinpointed five instructional objectives which professional development training must include. Teachers must be able to analyze various AT options from high-tech to low-tech which would be effective for their students and employ the best options in the prescribed method. Teachers must also understand that technology changes and AT capabilities will improve over time. Finally, teachers must be able to correct common errors with AT in the classroom and transition to alternate devices if the AT error cannot be resolved quickly.

Gap analysis was performed on the existing professional development courses using the five objectives from the task analysis. Current courses provided a plethora of knowledge related 
to the employment of AT in the classroom and provided satisfactory coverage of the impact of technology changes to the teachers. However, the other three objectives are not covered to the extent needed by the ESE teachers. This limitation to existing professional development courses led to recommendations for improvement.

ESE teachers require training on analysis of AT options which are available. They must be able to understand the benefits of low-, mid-, and high-tech AT and determine when each type can be used most effectively.

ESE teachers need to be able to choose AT alternatives based upon the needs of their students. They should understand the pros and cons of each alternative and how it can support students. The teacher should also understand UDL and how the AT alternatives could benefit students regardless of their disabilities or impairments.

Finally, ESE teachers need to have basic troubleshooting skills for the AT devices in their classrooms. Acquisition of these skills would reduce the impact on school staff having to come into the classroom to resolve minor issues. Teachers could also reduce the length of time the AT is unavailable and minimize disruptions in the classroom. 


\section{Appendix A: Demographic Survey}

\section{Demographic Survey}

Thank you for volunteering to participate in this research. This study will consist of a series of three surveys over a period of no more than 45 days. There will be periods of data analysis between each of the rounds. The goal is to identify the major training limitations hindering your ability to effectively use assistive technology in the classroom.

Twenty teachers will be randomly selected for this study. The information provided below will allow the researcher to ensure a broad coverage of experience for this research. You will be contacted if you have been selected and you will be expected to complete all three surveys. If you cannot meet this expectation please do not volunteer.

Please return the completed survey with your signed consent form to the primary researcher, David Schaaf, at ds1954@nova.edu.

\section{Demographics:}

1. Name:

2. Gender:

3. Current Grade Level Teaching:

4. Years Teaching in Current Grade Level:

5. Identify other grade levels you have taught and how many years in each level:

6. Teacher Certifications Earned (Year earned)::

Identification Number: (assigned by investigator to maintain anonymity)

Identification number to be used on future correspondence in place of name. 


\section{Appendix B: Delphi Round One Survey}

\section{Assistive Technology Survey}

This study consists of a series of questionnaires which will identify the major training limitations hindering the ability of Florida teachers to effectively use assistive technology in the classroom. This survey requests you provide broad information on what training limitations have kept you from using assistive technology or pursuing certification. It also requests you provide a list of certifications you plan to pursue in the next two-three years.

All participants' responses from round one will be edited, combined, and summarized. The summary responses will be provided to the participants in round two. At that time, you will be asked to rank the top issues along with rationale for your decision. The relative priority of the issues based upon the summarization of the round two surveys will then be presented to you in round three. During round three, you will be asked to reconsider your rankings with the rationale supporting your decision. The results of the round three surveys will be used to identify instructional content which needs to be in professional development curriculum.

Thank you for participating in this research.

\section{Barriers to the Use of Assistive Technology:}

Previous studies have identified issues which have impacted teachers' ability to use assistive technology in the classroom to support exceptional students. Please review the following list as you answer question one:

- Knowledge of assistive technology (includes training, research, experimentation, conditions for use)

- Personal technology proficiency

- IEP planning and support

- Student motivation

- Student assessment

- Administrative issues (policies, facilities)

1. Have you ever encountered a situation (or situations) where you needed to use assistive technology in the classroom for an exceptional student but have not been able to due to a lack of training? Please identify the situation(s) and explain why you were not able to use assistive technology. You can identify more than one training limitation.

2. Were you able to effectively use this assistive technology later? If so, how did you overcome the barriers?

\section{Teacher Certification:}

3. Please identify certifications you wish to earn but have not yet. Explain the barriers which have kept you from pursuing these certifications. 


\section{Appendix C: Analysis of First Round Survey}

\section{Teacher Comments and Coding}

The data gathered from the teachers on the first round survey were coded to identify limitations which impacted the teachers' ability to use AT in the classroom and the resources they used to overcome these limitations. The coded data from the first round survey are listed below:

\section{Teacher One:}

[At my previous school I had] a nonverbal student with ASD [Autism Spectrum Disorder], and I wanted to provide her with communication supports, but I was uncertain \{CODE/Limitation: Uncertainty on which AT to use to support various students' needs $\}$ where to begin. I wanted to provide her with picture cards, but we did not have resources $\{\mathrm{CODE} /$ Limitation: Lack of Resources\} like Boardmaker available, and I had no monetary support $\{\mathrm{CODE} /$ Limitation: Lack of Resources $\}$ to purchase it. AT was not on her IEP, and the SLP never worked with her on anything but her very limited verbalizations. In the end, I was not able to help her during the year I had her as a student. It was disappointing, because she had a lot of potential in that area. If I had greater resources and experience $\{\mathrm{CODE} /$ Limitation: Lack of Experience $\}$, I think she would have thrived on a voice-output device, and I'm sorry I couldn't give her that chance.

[My current school has] Boardmaker (and more), and the SLP \{CODE/Resource: Worked with Speech-Language Pathologist $\}$ was able to show me how to use it during pre-planning, so I had everything ready to go when my students arrived. I was able to implement it fully with access to the program, and the continued minor support of my SLP. Not only that, I was able to move on to voice output devices for multiple students.

\section{Teacher Two:}

Sometimes there is a lack of available equipment $\{\mathrm{CODE} /$ Limitation: Lack of resources $\}$ or malfunctions with the equipment $\{\mathrm{CODE} / \mathrm{Limitation}$ : Malfunctions with AT $\}$ that have made it difficult to have technology unavailable and working for the 
student. I definitely think that I lack knowledge of technology software in general, as far as what is available in the market \{CODE/Limitation: Lack of Knowledge of AT Available in the Market Place $\}$ and available specifically to me at my school \{CODE/Limitation: Lack of Knowledge of AT Available at the School $\}$ that would be an appropriate fit for the student. Additionally, being familiar $\{$ CODE/Limitation: Unfamiliarity with how AT works to support students' needs $\}$ with creating items (activities, communication boards, etc.) on Touchchat or Boardmaker Studio makes it harder to use with students. I have never had a formal training with either software so I use it $\{$ CODE/Resource: Hands-On Use $\}$ to the best of my ability and have just discovered things through trial and error $\{\mathrm{CODE} /$ Resource: Trial and Error $\}$. Not the most efficient way, but that is how a lot of my experiences and use with assistive technology have been.

I have overcome barriers mostly again through trial and error \{CODE/Resource: Trial and Error\}. I have collaborated a great deal with coworkers \{CODE/Resource: Collaboration with Other Teachers $\}$ on how they have used technology, and observed them \{CODE/Resource: Observed Other Teachers $\}$ using it to learn new things and see how I could apply those same techniques in my own classroom. I have definitely had to be persistent $\{$ CODE/Resource: Persistence $\}$ in trying technology different ways $\{\mathrm{CODE} /$ Resource: Experimenting with AT $\}$ to find the most effective uses of the technology for my students.

\section{Teacher Three:}

When I was in new teacher, I was not able to use all of the assistive technology available in my classroom due to the lack of training $\{\mathrm{CODE} /$ Limitation: Lack of Training . My students use switches for communication purposes and to access material in the classroom. Even though I had a basic knowledge of switches, I was unable to use them in a more advanced way (i.e. for students to actively participate during classroom academics by interacting with the material presented on the laptop and projected on a screen). I partnered with the Speech-Language Pathologist $\{\mathrm{CODE} /$ Resource: Worked with the Speech Language Pathologist $\}$, the Technology Specialist $\{$ CODE/Resource: Worked with the Technology Specialist $\}$, and the Occupational Therapist $\{\mathrm{CODE} /$ Resource: Worked with the Occupational Therapist $\}$. 
They were able to assist me with various assistive technology (including a wireless switch) and show me ways to effectively use it with my class.

I have been able to effectively use the assistive technology and have learned different ways to use the switches. One of the main ways that I have overcome barriers is by using $\{\mathrm{CODE} /$ Resource: Hands-On Use $\}$ the assistive technology (including step switches, wireless switches, etc.) frequently. This has enabled me to expand how I use the switches with my students, and I am able to model how to effectively use the technology with my teacher assistants, so they are able to work with the assistive technology as well.

\section{Teacher Four:}

I am fairly lacking in use [CODE/Limitation: Lack of Experience $\}$ of boardmaker, go talk and touch chat. I can get by with what is already on the ipads, if that is the case but am unfamiliar \{CODE/Limitation: Unfamiliarity with how AT works to support students' needs $\}$ with how to create new ones. I was very unfamiliar with the mimio.

With the mimio, I reviewed the online training videos $\{$ CODE/Resource: Online Training\} and familiarized myself with many of the tool's features however there is still quite a bit to learn.

\section{Teacher Five:}

I was not familiar $\{\mathrm{CODE} /$ Limitation: Unfamiliarity with how AT works to support students' needs $\}$ with the Mimio but have become more familiar with it. We have had a couple of short trainings $\{\mathrm{CODE} / \mathrm{Resource:} \mathrm{Attended} \mathrm{training \}} \mathrm{for} \mathrm{it.} \mathrm{I} \mathrm{was}$ not sure $\{\mathrm{CODE} /$ Limitation: Uncertainty on which AT to use to support various students' needs $\}$ of a video magnification system that was required for a vision impaired student but I have become familiar with it just by using it \{CODE/Resources: Hands-On Use $\}$.

By practicing $\{$ CODE/Resources: Practicing with AT $\}$ and becoming familiar with [the Mimio and video magnification system] allowed me to use them. I have asked other teachers $\{\mathrm{CODE} /$ Resources: Collaboration with other teachers $\}$ how to do things and attended training \{CODE/Resources: Attended training \} for Mimio when available. 


\section{Teacher Six:}

My first experience with a student using assistive technology took place about ten years ago. I was in a self-contained class with students ranging in grades Kindergarten through second grade. I had a student transfer out of state into my classroom. The student utilized a voice generating device as a support to her communication. Even though I had limited experience \{CODE/Limitation: Lack of Experience $\}$ with this specific device, I was able to navigate through the files I have been able to have access to resources or support staff that have been able to provide me with almost immediate training when I have come across a new type of communication system.

I was able to get training $\{\mathrm{CODE} /$ Resource: Attended training $\}$ on unique features and general use with my new student almost immediately after the student enrolled. I have also obtained support from the onsite speech language pathologist $\{\mathrm{CODE} /$ Resource: Worked with the Speech-Language Pathologist $\}$ or the school technology resource teacher $\{\mathrm{CODE} /$ Resource: Worked with the Technology Resource Teacher\}.

\section{Teacher Seven:}

Most of the assistive technology that I use in my classroom has more capabilities than I've been trained on $\{\mathrm{CODE} /$ Limitation: Lack of Training $\}$. I'm able to use them for their basic functions or whatever functions I've learned in previous trainings, but in most cases, the tech is able to perform more functions than what I've been trained on. Additionally, I have students with visual impairments with technology that I feel that I use on the most basic level due to a lack of thorough training $\{\mathrm{CODE} /$ Limitation: Lack of Training $\} /$ practice $\{\mathrm{CODE} /$ Limitation: Lack of Experience $\}$. Often, I look up online tutorials $\{\mathrm{CODE} /$ Resource: Online Training $\}$ for assistive technology and try to trouble shoot.

Often times, I learn how to effectively use certain assistive technology or how to better use the assistive technology by participating in weekly professional learning communities (PLC) \{CODE/Resource: Participating in Professional Learning Communities (PLC) \}. There, my fellow teachers and I are able to share expertise and 
work collaboratively $\{\mathrm{CODE} /$ Resource: Collaborate with Other Teachers $\}$ to improve teaching skills and to offer assistance with training in assistive technology. 


\section{Appendix D: Delphi Round Two Survey}

\section{Assistive Technology Survey}

This survey is the second in a series of questionnaires which will identify the major training limitations hindering the ability of Florida teachers to effectively use assistive technology in the classroom. The first survey requested broad information on what training limitations have kept you from using assistive technology and how the limitations were overcome. All participants' responses from round one were combined and summarized for this survey.

This survey asks you to select the top five reasons for not using assistive technology and top five methods the limitations were overcome. The items for these two questions were pulled from data in the first survey. Once you have selected the top five of each section, rank them in order of importance or applicability to you personally with the most important listed as number one, second as number two and so on for the top five. Finally, provide a brief rationale for your ranking of each item.

The results of this survey will be summarized to identify a relative priority of the limitations and methods for overcoming the limitations. These results will then be presented to you in round three. During round three, you will be asked to reconsider your rankings based upon the relative priority from all teachers. Again you will be asked to provide the rationale supporting your decision. The results of the round three survey will be used to identify instructional content which needs to be in professional development curriculum.

Thank you for participating in this research. 


\section{Limitations to the Use of Assistive Technology (AT):}

The following limitations were provided by teachers during the first round survey and are in alphabetical order to remove any sense of priority. Select the top five limitations and place them in the area below with limitation most relevant to you as number one, the second as number two, and so on. Below each limitation provide a brief explanation of why you placed this limitation in this position.

- Lack of experience using needed AT

- Lack of knowledge of AT available in the market place

- Lack of knowledge of AT available at school

- Lack of resources to learn about AT

- Lack of training on needed AT

- Malfunctions with AT

- Uncertainty on which AT to use to support various students' needs

- Unfamiliarity with how AT works to support students' needs

1.

Rationale for rank:

2.

Rationale for rank:

3.

Rationale for rank:

4.

Rationale for rank:

5.

Rationale for rank: 


\section{Resources Used to Overcome Limitations:}

The following resources which overcame limitations were provided by teachers during the first round survey and are in alphabetical order to remove any appearance of priority. Select the top five resources and place them in the area below with the resources most relevant to you as number one, the second as number two, and so on. Below each resource provide a brief explanation of why you placed this resource in the specific position.

- Attended training courses

- Collaborated with other teachers

- Experimented with AT

- Hands-On Use of AT

- Observed other teachers using AT

- Participating in Weekly Professional Learning Communities (PLCs)

- Persistence

- Practicing with AT

- Reviewed online training

- Trial and error

- Worked with Occupational Therapist

- Worked with Speech Language Pathologist

- Worked with Technology Specialist/Technology Resource Teacher

1.

Rationale for rank:

2.

Rationale for rank:

3.

Rationale for rank:

4.

Rationale for rank:

5.

Rationale for rank: 


\section{Appendix E: Analysis of Second Round Survey}

\section{Second Round Ranking}

The following two tables display how the teachers ranked each of the limitations and

resources. The right column shows the total value points each limitation and resource received.

The limitations and resources are sorted by their total value points.

\begin{tabular}{|c|c|c|c|c|c|c|}
\hline SECOND ROUND & Numk & ach & ting & tion & mber: & \\
\hline Limitations & 1 & 2 & 3 & 4 & 5 & Total Value Points \\
\hline Malfunctions with $\mathrm{AT}$ & 4 & 0 & 0 & 0 & 2 & 22 \\
\hline Lack of training on needed AT & 1 & 2 & 1 & 1 & 2 & 20 \\
\hline Lack of experience using needed AT & 0 & 1 & 4 & 1 & 1 & 19 \\
\hline Lack of knowledge of AT available in the market place & 1 & 3 & 0 & 1 & 0 & 19 \\
\hline Lack of knowledge of AT available at school & 2 & 0 & 1 & 2 & 1 & 18 \\
\hline Uncertainty on which AT to use to support various students' needs & 1 & 1 & 1 & 1 & 0 & 14 \\
\hline Lack of resources to learn about AT & 0 & 1 & 1 & 2 & 1 & 12 \\
\hline Unfamiliarity with how AT works to support students' needs & 0 & 1 & 1 & 1 & 0 & 9 \\
\hline & $\begin{array}{l}\text { NOTE: } \\
\text { Only se }\end{array}$ & & $\begin{array}{l}\text { hes } \\
\text { five }\end{array}$ & & & \\
\hline
\end{tabular}

\begin{tabular}{|c|c|c|c|c|c|c|}
\hline SECOND ROUND & Numb & che & $\mathrm{ng}$ & cea & ber: & \\
\hline Resources & 1 & 2 & 3 & 4 & 5 & Total Value Points \\
\hline Worked with Speech Language Pathologist & 2 & 1 & 3 & 2 & 0 & 27 \\
\hline Practicing with AT & 2 & 0 & 1 & 2 & 2 & 19 \\
\hline Trial and error & 1 & 2 & 0 & 2 & 1 & 18 \\
\hline Worked with Technology Specialist/Technology Resource Teacher & 0 & 2 & 1 & 1 & 0 & 13 \\
\hline Hands-On Use of AT & 1 & 1 & 0 & 1 & 1 & 12 \\
\hline Experimented with $\mathrm{AT}$ & 1 & 1 & 1 & 0 & 0 & 12 \\
\hline Participating in Weekly Professional Learning Communities (PLCs) & 1 & 0 & 0 & 1 & 2 & 9 \\
\hline Collab orated with other teachers & 1 & 0 & 1 & 0 & 1 & 9 \\
\hline Worked with Occupational Therapist & 0 & 1 & 1 & 0 & 0 & 7 \\
\hline Persistence & 0 & 0 & 1 & 0 & 1 & 4 \\
\hline Reviewed online training & 0 & 1 & 0 & 0 & 0 & 4 \\
\hline Attended training courses & 0 & 0 & 0 & 1 & 0 & 2 \\
\hline Observed other teachers using AT & 0 & 0 & 0 & 0 & 1 & 1 \\
\hline & $\begin{array}{l}\text { NOTE } \\
\text { Trial a }\end{array}$ & & & & & \\
\hline
\end{tabular}




\section{Appendix F: Delphi Round Three Survey}

Assistive Technology Survey

This survey is the third in a series of questionnaires related to the use of assistive technology in the classroom. The goal of this survey is to develop a consensus among the teachers on the major training limitations hindering the ability of Florida teachers to effectively use assistive technology and the resources which have helped overcome these limitations.

The second survey allowed Florida ESE teachers to rank the limitations and resources which were identified in the first survey. In the following sections, the highest ranked limitations and resources are identified. You will be asked what you feel are the top three limitation faced by ESE teachers and the top three resources which provide the biggest benefit. You may keep your top ranked limitation and resource from the second survey or you can decide to change it. Your individual rankings are included as an attachment.

The results of this survey will be provided to the district and school administrators to identify best practices to improve the implementation of assistive technology and instructional content which needs to be added or modified in professional development curriculum. Your individual comments will not be included in the final report but the main points will be addressed.

Thank you for participating in this research. 


\section{Limitations to the Use of Assistive Technology (AT):}

The limitations listed below were ranked by ESE teachers during the second round survey and are listed in order from highest priority to lowest priority. The number of points the limitation received are listed in parentheses. The rationale provided by the teachers for selecting the limitations is also included.

Based upon the opinions provided by the teachers, use the space below to rank what you feel are the top three limitations which impacts effective use of assistive technology in the classroom. You can change your ranking from the second survey. Your responses from survey two are included in this package for your reference. If your opinions of the importance of the limitations have changed, explain what caused the change.

1 .

2.

3.

Rationale for the change in the ranking:

\section{Overall Results from Second Round Survey:}

1. Malfunctions with AT (22)

Rationale:

- Sometime updates are needed and only the Techcon at our school is authorized to do that.

- I have often found that even when AT is available, some is expensive so we have limited resources to use. Additionally, if the equipment has been used a lot or is old and not working well, it can be hard to get it fixed or take a long time. Also, there are sometimes difficulties with Wi-Fi and slow internet connections that limit the use of AT in my classroom.

- I have a variety of AT to use in the classroom, but there are times when it does malfunction. Since my class relies a great deal on AT, this can effect a lesson and how my students interact during the day.

- Often times, I'll be set up and ready to go and the AT fails to perform its function sometimes resulting in behaviors from students anticipating the use of the device.

- Have multiple ways to use in the classroom but it does not always work correctly.

- Our iPads don't always work every day or some apps don't. 
2. Lack of training on needed AT (20)

Rationale:

- This mostly applies to the para-educators since there is limited time teachers have to work with the para-educators to inform/training them on how to navigate through specific student communication/apps.

- You can always learn to do something better.

- I have partnered with different support staff to help train me on the needed AT for my classroom, so even though this was a big limitation, I have learned so much from the support staff that I listed this as not as relevant. Even so, there is always new technology and new ways to use technology, so I feel that I can always learn more.

- Training time is so limited with such demanding schedules at work. Even the trainings we do have seem like brief overviews with very little time to practice and master skills.

- Most use is by quick example. No idea how to trouble shoot.

- We aren't trained on the resources out there available to use.

3. Lack of knowledge of AT available in the market place (19)

Rationale:

- The school SLP and the Techcon are typically the ones that get the most updated information regarding AT. They make recommendations to our students based on the student's abilities and match up the student to the most compatible AT system for them.

- There could be something perfect for your student out there, and you could be able to get the funding, but if you don't know about it, what good would it do?

- I realize that technology is always improving, including AT, but I am unfamiliar with what the newest AT is available and where to look to find this technology, so this does limit how I use AT in my classroom.

- I had never heard of some of the technology that was asked on the first survey.

4. Lack of experience using needed AT (19)

Rationale:

- The para-educators might not have the experience needed to facilitate instructional support for students requiring specific communication systems

- This only occurs if a student using a totally different system transfers to our school or if by some reason all school-provided trainings were missed due to extenuating circumstances

- Many types of AT I have just learned through trial and error. I don't think this is always the most effective way to use it, and when it is unsupported or without 
guidance it is easier to give up on using that particular method of AT. So even when I know AT is available, I am not always using it or able to use it effectively.

- This was more relevant when I first started, but I do still find that there is technology that I could use in my classroom that I do not have the experience needed to utilize the technology effectively.

- I just haven't used some AT enough to feel comfortable using it on a daily basis with my students.

- New teacher; AT never used with previous teacher

5. Lack of knowledge of AT available at school (18)

Rationale:

- Honestly, I don't even know what is out there to help with a student's needs. It is easy to identify an area of need but difficult and time consuming to research solutions, not to mention if you find one, having the money to be able to use it in the classroom.

- There are so many teaching responsibilities and resources available it can be very difficult to keep track and find what is needed for a specific student.

- You can't use what's not available. And it's easy to assume it's not available, if no one is showing it to you.

- I know there is a lot of technology available at the school that I'm either not aware of or I don't know who to ask for support.

- I don't know what can be used and what can't be used at our school.

6. Uncertainty of which AT to use to support various students' needs (14)

Rationale:

- Sometimes you can get paralyzed by the different options, or be unsure if something would be helpful or not.

- I generally consult with Speech Language, OT, PT and or AT to decide which device(s) would benefit particular students. With so many students and so little time, it's difficult to find technology that works for each one of them. Especially if I'm not sure what technology we have or what its function is.

7. Lack of resources to learn about AT (12)

Rationale:

- I don't think there are many professional development opportunities about AT that I have ever heard about. I'm not really sure of other resources to even learn about AT besides the possibility of professional development or trying to search the internet. It's hard to find resources for AT if you don't even know what's out there in the first place.

- There could be something perfect for your student out there, but if you don't know about it, would you look?

- Our school has excellent support staff to assist with the AT that we have at the school, but I am unsure of whether there are other AT resources within the district that may be beneficial to my students.

- We had one AT teacher for a high demand school.

- We aren't notified of the latest resources out there. 
8. Unfamiliarity with how AT works to support students' needs (9) Rationale:

- Not sure how to assess needs

- Limited knowledge on all different types of AT 


\section{Resources Used to Overcome Limitations:}

The resources listed below were ranked by ESE teachers during the second round survey and are listed in order from highest priority to lowest priority. The number of points the resource received are listed in parentheses. The rationale provided by the teachers for selecting the resources is also included.

Based upon the opinions provided by the teachers, use the space below to rank what you feel are the top three resources which enhance effective use of assistive technology in the classroom. You can change your ranking from the second survey. Your responses from survey two are included in this package for your reference. If your opinions of the importance of the resources have changed, explain what caused the change.

1.

2.

3.

Rationale for the change in the ranking:

\section{Overall Results from Second Round Survey:}

1. Worked with Speech Language Pathologist (27)

Rationale:

- The school SLP has been my first contact when I am trying to learn a new system or if a system modification is needed for a student.

- I have become better at using AT after working together with the Speech language pathologist for AT to assist with student communication.

- She is passionate and knowledgeable, and that has helped and, more importantly, inspired me.

- The Speech Language Pathologist has helped me as much as the Occupational Therapist by providing different types of AT, how to use the AT, and by troubleshooting problems as they arise.

- Our Speech Language Pathologist is very knowledgeable and very in demand. When she is able to, she does a great job of providing my6 class with AT and giving us an overview in how it should function. She also trouble shoots issues we may be having with said AT.

2. Practicing with AT (19)

Rationale:

- One of the first things I always try to do is have a guided mini lesson from our SLP to practice how I should carry this over to the classroom with my students.

- The more time you put into it, the better you become.

- I learn more quickly by actually using something, so this has really helped me overcome my limitations. I placed this first, because even though I have had a lot of 
help from the support staff, if I did not continually practice using the AT, I would be less likely to use it.

- The more I practice and play around with the AT myself, the more comfortable and proficient I become with it which, in turn, benefits my students.

- I like to use things on my own.

3. Trial and Error (18)

Rationale:

- Sometimes you learn just from trying it yourself and making mistakes.

- Trying different things in my classroom and seeing how it goes has really helped me be more comfortable with AT in my classroom.

- If at first you don't succeed, try, try again. Trying it and seeing what works is a much better teacher than any online module.

- I find that I am able to trouble shoot a lot of issues with AT by simple trial and error, or through the trial and error of a coworker.

- I am a hands-on learner.

4. Worked with Technology Specialist/Technology Resource Teacher (13)

Rationale:

- The techcon [technology specialist] onsite always cooperates to provide all support to meet student needs. In addition, he collaborates with our school SLP to support the technology that is needed.

- I have been able to work with the school technology specialist to help with questions and troubleshoot using AT in my classroom on numerous occasions.

- The Technology Specialist has helped more by troubleshooting when problems arise with AT in the classroom to help keep everything working well, so he tends to help more as needed, but definitely still has helped to overcome my limitations.

5. Hands-On Use of AT (12)

Rationale:

- Sometimes you learn just from trying it yourself and making mistakes.

- Experience, the best teacher.

- This is how most of us need to learn how to use new AT.

6. Experimented with AT (12)

Rationale:

- Most of the time, I practice and play with AT to figure out what the full function and capabilities of the device(s) is.

- I am a hands-on learner.

- I have experimented with some technology on my own.

7. Collaborated with other teachers (9)

Rationale:

- One of the biggest ways I have overcome limitations with TA usage is by collaborating with coworkers who are more comfortable and experienced. It has 
allowed me to trouble shoot quickly during the day and ask questions and get help and feedback in a non-threatening, informal way.

- We learn together and share technology issues and how to work things.

8. Participating in Weekly Professional Learning Communities (PLCs) (9)

Rationale:

- The weekly PLC group has been beneficial in providing new ideas for using AT by hearing about what is working in the classroom. Additionally, we are able to bounce off ideas during this time to find solutions to problems we may be having in our class with AT and to find new ways to use AT with our students.

- Lots of tips and tricks are shared during PLCs that have helped overcome a number of AT complications.

- We all share our knowledge of what we know.

9. Worked with Occupational Therapist (7)

Rationale:

- The Occupational Therapist has provided me with several different forms of AT, and he has made multiple modifications to help make things, by using AT, in my classroom more accessible to my students. He has provided me with a great deal to help overcome my limitations.

10. Persistence (4)

Rationale:

- The more I have used AT in my classroom, the easier it gets and the more I am able to use it and try new things. Just trying again and again until it works has helped a great deal to make it easier for me to use AT.

- A lot of people quit when tech is buggy at the beginning. If you keep going, the problems (should) decrease and the rewarding successes start to outweigh everything else.

11. Reviewed online training (4)

Rationale:

- None provided

12. Attended training courses (2)

Rationale:

- $\quad$ None provided

13. Observed other teachers using AT (1)

Rationale:

- I have learned shortcuts or a new navigation strategy from watching others. 


\section{Appendix G: Analysis of Third Round Survey}

\section{Third Round Ranking}

The following two tables display how the teachers ranked each of the limitations and resources. The right column shows the total value points each limitation and resource received. The limitations and resources are sorted by their total value points.

\begin{tabular}{|l|c|c|c|c|c|c|}
\hline THIRD ROUND & \multicolumn{2}{l|}{ Number of teachers ranking limitation as number: } & $\mathbf{5}$ & Total Value Points \\
\hline Limitations & $\mathbf{1}$ & $\mathbf{2}$ & $\mathbf{3}$ & $\mathbf{4}$ & $\mathbf{5}$ \\
\hline Malfunctions with AT & 3 & 3 & 1 & 0 & 0 & 30 \\
\hline Lack of training on needed AT & 3 & 1 & 1 & 0 & 0 & 22 \\
\hline Lack of knowledge of AT available in the market place & 0 & 3 & 2 & 0 & 0 & 18 \\
\hline Lack of knowledge of AT available at school & 2 & 0 & 1 & 0 & 0 & 13 \\
\hline Lack of experience using needed AT & 0 & 2 & 1 & 0 & 0 & 11 \\
\hline Uncertainty on which AT to use to support various students' needs & 1 & 0 & 2 & 0 & 0 & 11 \\
\hline Lack of resources to learn about AT & 0 & 0 & 1 & 0 & 0 & 3 \\
\hline Unfamiliarity with how AT works to support students' needs & 0 & 0 & 0 & 0 & 0 & 0 \\
\hline
\end{tabular}

\begin{tabular}{|c|c|c|c|c|c|c|}
\hline \multirow{2}{*}{\begin{tabular}{|l|} 
THIRD ROUND \\
Resources \\
\end{tabular}} & \multicolumn{5}{|c|}{ Number of teachers ranking resource as number: } & \multirow[b]{2}{*}{ Total Value Points } \\
\hline & 1 & 2 & 3 & 4 & 5 & \\
\hline Worked with Speech Language Pathologist & 4 & $\overline{2}$ & 1 & 0 & 0 & 31 \\
\hline Worked with Technology Specialist/Technology Resource Teacher & 1 & 2 & 0 & 0 & 0 & 13 \\
\hline Practicing with AT & 2 & 0 & 1 & 0 & 0 & 13 \\
\hline Trial and error & 0 & 3 & 0 & 0 & 0 & 12 \\
\hline Hands-On Use of AT & 1 & 1 & 0 & 0 & 0 & 9 \\
\hline Participating in Weekly Professi onal Learning Communities (PLCs) & 1 & 0 & 1 & 0 & 0 & 8 \\
\hline Experimented with AT & 0 & 1 & 1 & 0 & 0 & 7 \\
\hline Collaborated with other teachers & 0 & 0 & 2 & 0 & 0 & 6 \\
\hline Worked with Occupational Therapist & 0 & 0 & 2 & 0 & 0 & 6 \\
\hline Persistence & 0 & 0 & 1 & 0 & 0 & 3 \\
\hline Reviewed online tr aining & 0 & 0 & 0 & 0 & 0 & 0 \\
\hline Observed other teachers using AT & 0 & 0 & 0 & 0 & 0 & 0 \\
\hline Attended training courses & 0 & 0 & 0 & 0 & 0 & 0 \\
\hline
\end{tabular}

\section{Division of Limitations into Quartiles}

In order to determine if a consensus had been achieved, the limitations were assessed by breaking them down into quartiles. The first step was to calculate the median of all value points. This value is also called $\mathrm{Q}_{2}$. All limitations with value points greater than or equal to $\mathrm{Q}_{2}$ were in the top half. The median of the value points from the top half of the limitations was calculated. This value is called $\mathrm{Q}_{3}$. Limitations with value points greater than or equal to $\mathrm{Q}_{3}$ were in the top quarter. 
The value $\mathrm{Q}_{2}$ and $\mathrm{Q}_{3}$ were calculated for both the second and third round surveys. The limitations in the top quarter for the second and third rounds are listed in the table below.

\begin{tabular}{|l|c|c|}
\hline & Second Round & Third Round \\
\hline $\mathrm{Q}_{2}$ & 18.5 & 12 \\
\hline $\mathrm{Q}_{3}$ & 19.5 & 20 \\
\hline
\end{tabular}

\begin{tabular}{|l|l|}
\hline TOP QUARTER - Second Round & TOP QUARTER - Third Round \\
\hline Malfunctions with AT & Malfunctions with AT \\
\hline Lack of training on needed AT & Lack of training on needed AT \\
\hline
\end{tabular}

The limitations of Malfunctions with AT and Lack of training on needed AT were in the top quarter for both the second and third rounds.

The same analysis was performed with the limitations after the two "knowledge" limitations had been deleted. The results of this analysis are listed below.

\begin{tabular}{|l|c|c|}
\hline & Second Round & Third Round \\
\hline $\mathrm{Q}_{2}$ & 20 & 11.5 \\
\hline $\mathrm{Q}_{3}$ & 25 & 24 \\
\hline
\end{tabular}

\begin{tabular}{|l|l|}
\hline TOP QUARTER - Second Round & TOP QUARTER - Third Round \\
\hline Lack of training on needed AT & Malfunctions with AT \\
\hline Malfunctions with AT & Lack of training on needed AT \\
\hline
\end{tabular}

The limitations of Malfunctions with AT and Lack of training on needed AT were once again in the top quarter for both the second and third rounds. 


\section{Appendix H: Task Analysis}

\section{Topic Analysis}

The following table breaks up the knowledge required by the teacher into the six areas of the topic analysis. The analysis of this data will identify the content of instruction:

\begin{tabular}{|l|l|}
\hline Topic Analysis Areas & Required Teacher Knowledge \\
\hline Facts & $\begin{array}{l}\text { AT helps students with special needs } \\
\text { Not all AT will support students equally } \\
\text { Technology constantly changes }\end{array}$ \\
\hline Concepts & $\begin{array}{l}\text { Need alternatives to AT if there is a malfunction } \\
\text { Each student with special needs will need specific AT }\end{array}$ \\
\hline Attitudes & $\begin{array}{l}\text { Teacher will not use AT is he is uncertain about it } \\
\text { Teacher is often paralyzed by options } \\
\text { Teachers are willing to ask others for help }\end{array}$ \\
\hline Principles and Rules & $\begin{array}{l}\text { Problems with AT will remove the focus from the } \\
\text { student } \\
\text { Uncertainty limits effectiveness }\end{array}$ \\
\hline Procedures & $\begin{array}{l}\text { Process to determine why AT is not functioning } \\
\text { properly }\end{array}$ \\
\hline Interpersonal Skills & $\begin{array}{l}\text { Working with student, focused on them, not the AT } \\
\text { Talk to school staff for assistance }\end{array}$ \\
\hline
\end{tabular}

\section{Clustering of Essential Knowledge, Tasks, and Attitudes}

The clusters from the task analysis are listed below along with the applicable comments from the teachers and SMEs:

Cluster 1: AT in ESE leaves teachers paralyzed by options and causes uncertainty which limits their effectiveness

- Sometimes you can get paralyzed by the different options, or be unsure if something would be helpful or not 
- I generally consult with Speech Language, OT, PT, and/or AT to decide which device(s) would benefit particular students

- With so many students and so little time, it's difficult to find technology that works for each of them, especially if I don't know what we have to what its function is

- Sixty percent of teachers are not education majors

- Teaching Assistants make up the majority of instructors; they have zero training

Cluster 2: AT is unique to each student and, therefore, specific AT must be used to support individual students

- $\quad$ Partner with support staff to help with training

- New technology, new ways to use technology

- I know basic functions, but [the] tech can perform more functions than what I've been trained on

- I use technology on the most basic level due to lack of thorough training/practice

- Little time for training; training feels brief, overviews with little time to practice and master skills

- $\quad$ Most use is by quick example

- $\quad$ Only one AT teacher for a high demand school

- I can get by with what is on IPads but unfamiliar with how to create new one functions

Cluster 3: Technology is always changing and it is important to find sources of information on the new technology; sharing information is critical

- Never heard of AT listed

- Aren't aware of resources

- Limited training time for para-educators (teaching assistants)

- TAs work one-on-one with students

- No formal training on software

- Unaware of available professional development

- Sometimes get paralyzed by different options

- Unsure if something would be helpful or not 
- Need data to support decision

- I could not use AT in a more advanced way

Cluster 4: There is often some problem with the AT and it removes the focus of instruction from the student

- Technology sometimes does not work right

- Sometimes only updates required, need TechCon

- Technology not available for student

- $\quad$ Equipment may be old or not working well

- $\quad$ Long time to fix

- Slow connections in classroom

- Affects lessons and how student interact

- Set up and ready to use AT but it fails to perform its function resulting in poor behavior from students

- No idea how to troubleshoot problems

- Teachers need to be able to troubleshoot simple problems

Cluster 5: When the AT fails it is important to quickly determine why it failed, how to fix it, or identify an alternative to the AT

- Many times the problem is related to network issues

- Location of school causes connection issues

- Physical network problems cannot be changed

- Teachers must be able to adjust if devices are not available or are not working 


\section{Appendix I: Gap Analysis Matrix}

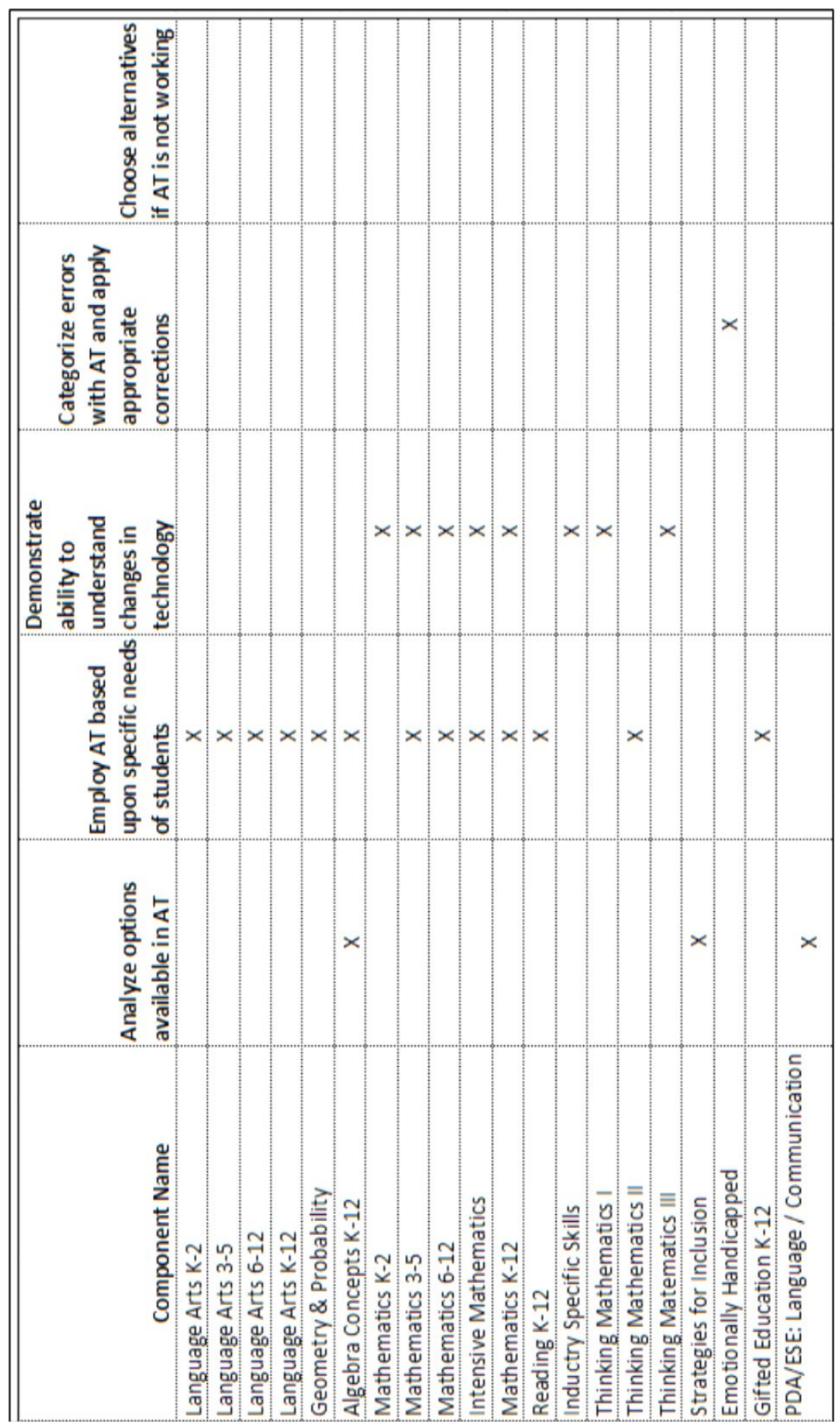




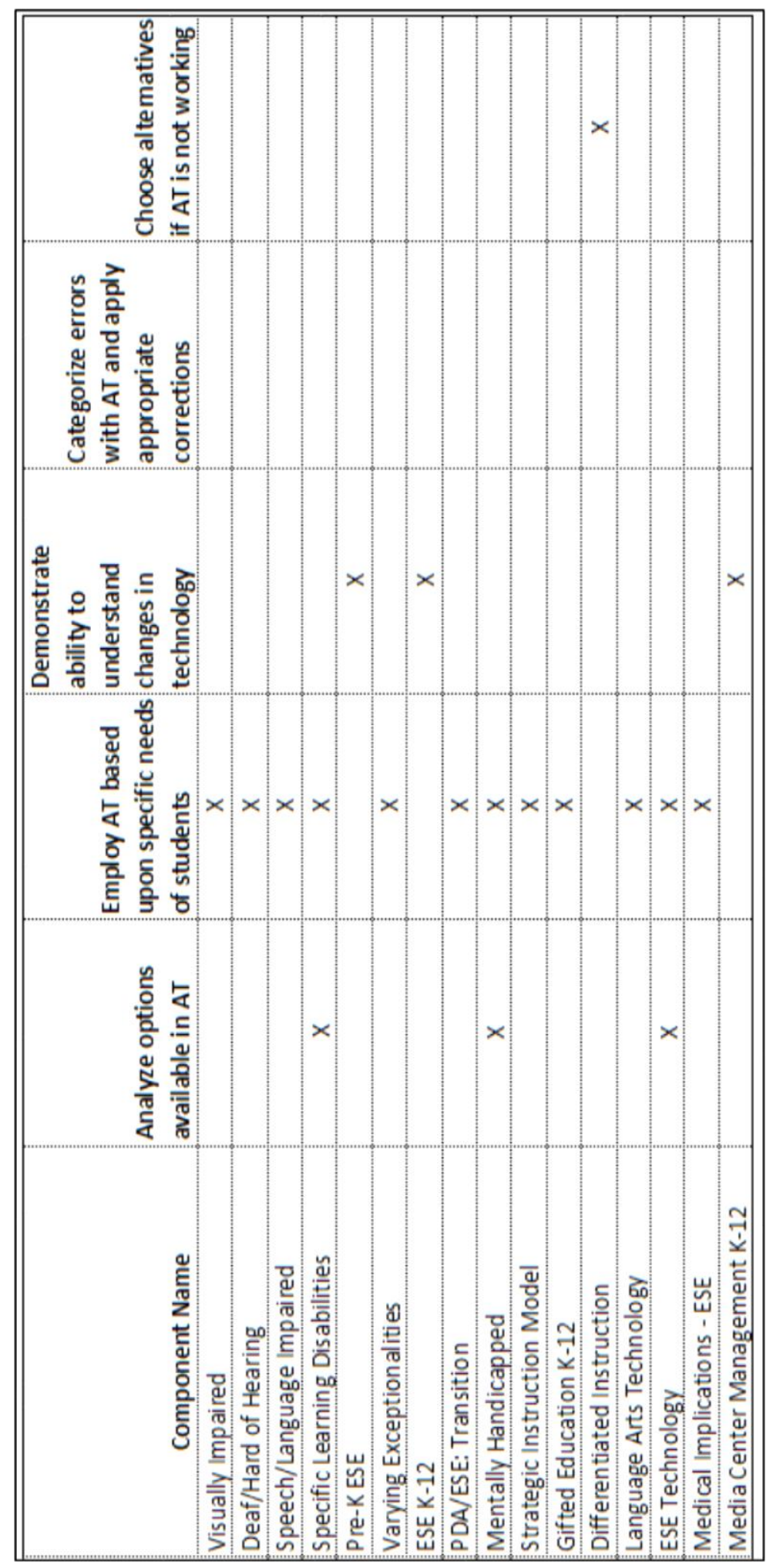




\section{Appendix $\mathbf{J}$}

\section{Nova Southeastern University IRB Protocol}


NOVA SOUTHEASTERN UNIVERSITY

Institutional Review Board

\section{MEMORANDUM}

To: $\quad$ David N Schaaf, Educational Specialist

College of Engineering and Computing

From: $\quad$ Ling Wang, Ph.D.,

Center Representative, Institutional Review Board

Date: $\quad$ December 1, 2015

Re: $\quad$ IRB \#: 2015-136; Title, “Assistive Technology Instruction in Teacher Professional Development"

I have reviewed the above-referenced research protocol at the center level. Based on the information provided, I have determined that this study is exempt from further IRB review under 45 CFR 46.101(b) ( Exempt Category 2). You may proceed with your study as described to the IRB. As principal investigator, you must adhere to the following requirements:

1) CONSENT: If recruitment procedures include consent forms, they must be obtained in such a manner that they are clearly understood by the subjects and the process affords subjects the opportunity to ask questions, obtain detailed answers from those directly involved in the research, and have sufficient time to consider their participation after they have been provided this information. The subjects must be given a copy of the signed consent document, and a copy must be placed in a secure file separate from de-identified participant information. Record of informed consent must be retained for a minimum of three years from the conclusion of the study.

2) ADVERSE EVENTS/UNANTICIPATED PROBLEMS: The principal investigator is required to notify the IRB chair and me (954-262-5369 and Ling Wang, Ph.D., respectively) of any adverse reactions or unanticipated events that may develop as a result of this study. Reactions or events may include, but are not limited to, injury, depression as a result of participation in the study, lifethreatening situation, death, or loss of confidentiality/anonymity of subject. Approval may be withdrawn if the problem is serious.

3) AMENDMENTS: Any changes in the study (e.g., procedures, number or types of subjects, consent forms, investigators, etc.) must be approved by the IRB prior to implementation. Please be advised that changes in a study may require further review depending on the nature of the change. Please contact me with any questions regarding amendments or changes to your study.

The NSU IRB is in compliance with the requirements for the protection of human subjects prescribed in Part 46 of Title 45 of the Code of Federal Regulations (45 CFR 46) revised June 18, 1991.

Cc: Gertrude Abramson, Ed.D. 


\section{References}

Ajuwon, P. M., Meeks, M. K., Griffin-Shirley, N., \& Okungu, P. A. (2016). Reflections of teachers of visually impaired students on their assistive technology competencies. Journal of Visual Impairment \& Blindness (Online), 110(2), 128.

Bausch, M. E., \& Ault, M. J. (2012). Status of assistive technology instruction in university personnel preparation programs. Assistive Technology Outcomes and Benefits, 8(1), 1-14.

Bouck, E. C. \& Flanagan, S. M. (2010). Virtual Manipulatives: What they are and how teachers can use them. Intervention in School and Clinic, 45(3), 186-191.

Bouck, E. C., Flanagan, S., Heutsche, A., Okolo, C. M., \& Englert, C. E. (2011). Teachers' initial and sustained use of an instructional assistive technology tool: Exploring the mitigating factors. Journal of Educational Multimedia and Hypermedia, 20(3), 247-266.

Bouck, E. C., \& Joshi, G. S. (2012). Assistive technology and mathematics education: Reports from the field. Journal of Computers in Mathematics and Science Teaching, 31(2), 115138.

Brownell, M. T., \& Leko, M. M. (2014). Preparing special educators to teach literacy. In P. T. Sindelar, E. D. McCray, M. T. Brownell, \& B. Lignugaris/Kraft (Eds.), Handbook of Research on Special Education Teacher Preparation (pp. 255-270). New York, NY: Routledge.

Burgstahler, S. (2011). Universal Design: Implications for Computing Education. ACM

Transactions on Computing Education, 11(3), 17. doi:10.1145/2037276.2037283

Coleman, M. B. (2011). Successful implementation of assistive technology to promote access to curriculum and instruction for students with physical disabilities. Physical Disabilities: Education and Related Services, 30(2), 2-22. 
Connor, C. \& Beard, L. A. (2015). Increasing meaningful assistive technology use in the classrooms. Universal Journal of Educational Research, 3(9), 640-642. Doi:

10,13189/ujer.2015.030908

Connor, C., Snell, M., Gansneder, B., \& Dexter, S. (2010). Special education teachers' use of assistive technology with students who have severe disabilities. Journal of Technology and Teacher Education, 18(3), 369-386.

Creswell, J. W. (2013). Qualitative Inquiry \& Research Design: Choosing Among Five Approaches ( $3^{\text {rd }}$ ed.). Los Angeles, CA: Sage Publications, Inc.

Dalkey, N. \& Helmer, O. (1963). An experimental application of the Delphi method to the use of experts. Management Science, 9(3), 458-467. doi: 10.1287/mnsc.9.3.458

Definitions, ESE Policies and Procedures, and ESE Administrators, Florida Administrative Code Rule 6A-6.03411. (2014).

Delbecq, A. L., Van de Ven, A. H., \& Gustafson, D. H. (1986). Group Techniques for Program Planning : a guide to nominal group and delphi processes. Middleton, WI: Green Briar Press.

Dell, A. G., Newton, D. A., \& Petroff, J. G. (2012). Assistive technology in the classroom (2 ${ }^{\text {nd }}$ ed.). Boston, MA: Pearson Education, Inc.

Florida Department of Education (FLDOE), Bureau of Educator Recruitment, Development and Retention. (2010). Professional Development System Evaluation Protocol: Protocol System, Third Cycle, 2010-2014.

Florida Department of Education (FLDOE), Bureau of Educator Recruitment, Development and Retention. (2012). Professional Development System Evaluation Protocol: Reviewer's Guide, Third Cycle, 2010-2014. 
Florida Department of Education (FLDOE), Bureau of Exceptional Education and Student Services. (2008). Statewide Response to Instruction/Intervention (RtI) Implementation Plan.

Florida Department of Education (FLDOE), Bureau of Exceptional Education and Student Services. (2011). Resources for Florida's teachers.

Florida Department of Education (FLDOE). (2014). Competencies and skills required for teacher certification in Florida, $21^{\text {st }}$ Edition.

Florida K-20 Education Code, Fla. Stat. Ann. § 1003 et seq. (LexisNexis, 2014).

Fowler, F. J., Jr. (2014). Survey Research Methods (5 ${ }^{\text {th }}$ ed.). Los Angeles, CA: Sage Publications, Inc.

Gay, L., Mills, G., \& Airasian, P. (2011). Educational research: Competencies for analysis and applications (10 ${ }^{\text {th }}$ ed.). Upper Saddle River, NJ: Pearson.

Gilakjani, A. P., Leong, L.-M., \& Ismail, H. N. (2013). Teachers' use of technology and constructivism. International Journal of Modern Education and Computer Science, 5(4), 49-63. doi:10.5815/ijmecs.2013.04.07

Hsu, C.-C. \& Sandford, B. A. (2007). The Delphi technique: Making sense of consensus. Practical Assessment, Research \& Evaluation, 12(10), 1-8.

Individuals with Disabilities Education Improvement Act of 2004, 20 U.S.C. $\S 1401$ et seq. (HeinOnline, 2006).

Instructional Personnel Certification, Florida Administrative Code Rule 6A-4.001. (2001).

Ludwig, B. G. (1994). Internationalizing extension: An exploration of the characteristics evident in a state university extension system that achieves internationalization (Doctoral dissertation). Retrieved from ProQuest Dissertations \& Theses Global. (9420985) 
Messinger-Willman, J., \& Marino, M. T. (2010). Universal Design for Learning and assistive technology: Leadership considerations for promoting inclusive education in today's secondary schools. NASSP Bulletin, 94(1), 5-16. doi:10.1177/0192636510371977

Moody, A. K. (2015). Procedures, considerations, and recommendations for the development of an assistive technology demonstration and lending sites. Journal of Special Education Technology, 30(3), 179-187. doi: 10.1177/0162643415619248

Morrison, G. R., Ross, S. M., Kalman, H. K., \& Kemp, J. E. (2011). Designing effective instruction $\left(6^{\text {th }}\right.$ ed.). Hoboken, New Jersey: John Wiley \& Sons, Inc.

Nelson, L. H., Lenihan, S., \& White, K. R. (2014). Preparation of teachers for children who are Deaf or Hard of Hearing. In P. T. Sindelar, E. D. McCray, M. T. Brownell, \& B. Lignugaris/Kraft (Eds.), Handbook of Research on Special Education Teacher Preparation (pp. 334-352). New York, NY: Routledge.

O’Malley, P., Jenkins, S., Wesley, B., Donehower, C., Rabuck, D., \& Lewis, M. E. B. (2013, April). Effectiveness of using iPads to build math fluency. Paper presented at the Council for Exceptional Children Annual Meeting, San Antonio, Texas.

Peterson-Karlan, G. R. (2015). Assistive technology instruction within a continuously evolving technology environment. Quarterly Review of Distance Education, 16(2), 61-76.

Provision of Free Appropriate Public Education (FAPE) and Development of Individual Educational Plans for Students with Disabilities, Florida Administrative Code Rule 6A6.03028. (2014).

Reeves, G. \& Jauch, L. R. (1978). Curriculum development through Delphi. Research in Higher Education, 8(2), 157-168.

Rose, D., \& Dalton, B. (2009). Learning to read in the digital age. Mind, Brain, and Education, 3(2), 74-83. doi:10.1111/j.1751-228X.2009.01057 
Rose, D. \& Meyer, A. (2002). Teaching every student in the digital age: Universal design for learning. Arlington, VA: Association for Supervision and Curriculum Development.

Schaaf, D. N. (2013). Assistive Technologies in Florida's Classrooms. Journal of Applied Learning Technology, 3(2), 6-12.

Sitlington, H. \& Coetzer, A. (2015). Using the Delphi technique to support curriculum development, Education + Training, 57(3), 306-321. doi: 10.1108/ET-02-2014-0010

Smith, D. D., \& Tyler, N. C. (2011). Effective inclusive education: Equipping education professionals with necessary skills and knowledge. Prospects, 41(3), 323-339. doi:10.1007/s11125-011-9207-5

Smith, S. J., \& Kennedy, M. J. (2014). Technology and teacher education. In P. T. Sindelar, E. D. McCray, M. T. Brownell, \& B. Lignugaris/Kraft (Eds.), Handbook of Research on Special Education Teacher Preparation (pp. 178-193). New York, NY: Routledge.

Sze, S. (2008). The effects of assistive technology on students with disabilities. Journal of Educational Computing Research, 37(4), 419-429.

Teclehaimanot, B., Mentzer, G., \& Hickman, T. (2011). A mixed methods comparison of teacher education faculty perceptions of the integration of technology into their courses and student feedback on technology proficiency. Journal of Technology \& Teacher Education, 19(1), 5-21.

U.S. Department of Education, Office of Special Education and Rehabilitation Services. (2010). Thirty-five Years of Progress in Educating Children with Disabilities through IDEA.

Van Laarhoven, T., \& Conderman, G. (2011). Integrating assistive technology into special education teacher preparation programs. Journal of Technology and Teacher Education, 19(4), 473-497. 
Van Laarhoven, T., Munk, D. D., Chandler, L. K., Zurita, L., \& Lynch, K. (2012). Integrating assistive technology into teacher education programs: Trials, tribulations, and lessons learned. Assistive Technology Outcomes and Benefits, 8(1), 32-47.

Yin, R. K. (2014). Case Study Research: Designs and Methods. (5 ${ }^{\text {th }}$ ed.). Thousand Oaks, CA: SAGE Publications, Inc. 